\title{
Urban-Rural Gradients of Ecosystem Services and the Linkages with Socioeconomics
}

\author{
Ying Hou1, 2*, Felix Müller, Bo Li2, Franziska Kroll 3 \\ 1 Christian Albrechts University of Kiel, Institute for Natural Resource Conservation, Olshausenstr. 75, D 24118 Kiel, Germany \\ 2 Beijing Normal University, College of Resource Science and Technology, Beijing, China 100875, Beijing, China \\ 3 Regierungspräsidium Darmstadt, Abteilung Arbeitsschutz und Umwelt Frankfurt, Gutleutstraße 114, D 60327 Frankfurt am \\ Main, Germany
}

\begin{abstract}
The principle of urban-rural gradients can reveal the spatial variations of ecosystem services and socioeconomic dimensions. The interrelations between ecosystem services and socioeconomics have scarcely been considered in the context of urban-rural areas. We investigated the spatial gradients and the mutual linkages of several ecosystem services and socioeconomic variables in the urban-rural areas of Leipzig, Germany, and Kunming, China. The results showed some regularities in the spatial patterns of ecosystem services and socioeconomic dimensions in both study areas. Habitat quality and f-evapotranspiration of Leipzig and habitat quality of Kunming demonstrated apparent increasing trends along all gradient patterns. However, the other ecosystem services presented divergent spatial variabilities in different gradient patterns. Road density, urban fabric and population density showed identical declining trends in both case study areas. Differently, household size, housing area as well as unemployment rate in Leipzig presented inconsistent spatial dynamics with considerable fluctuations. With regard to the gradient interrelations, road density, urban fabric and population density were strongly correlated with most ecosystem services in both case study areas. In contrast, the gradients of household size, housing area and unemployment rate of Leipzig showed inconsistent correlations with the ecosystem services gradients. Our study provides evidence to the argument that typical patterns of ecosystem service gradients do not exist in different urban-rural areas.
\end{abstract}

\section{Keywords:}

human-environmental systems, spatial dynamics, gradient patterns, quantitative, comparison, uncertainties

Submitted: 21 July 2014 / Accepted in revised form: 6 February 2015 / Published: 28 February 2015

\footnotetext{
*Corresponding author. Email: yhou@ecology.uni-kiel.de

(C) The Authors. 2015. Landscape Online. This is an Open Access article distributed under the terms of the Creative Commons Attribution License (http://creativecommons.org/licenses/by/4.0), which permits unrestricted use, distribution, and reproduction in any medium, provided the original work is properly cited.
} 


\section{Introduction}

\subsection{The role of ecosystem services in tackling the issue of human-environment interactions}

As a multidisciplinary principle, the concept of ecosystem services can be used to tackle the issue of human-environment interactions by linking natural sciences with social sciences. Ecosystem services cannot be tenable without human perception and use as it is defined as the benefits people acquire from natural system (Costanza et al., 1997; TEEB, 2010). The relationship between ecosystem services and human well-being can be either synergies or trade-offs, depending on which types of ecosystem services and human well-beings and what scales are considered (Duraiappah, 2011; Haines-Young and Potschin, 2010; MA, 2005; Raudsepp-Hearne et al., 2010). Human activities can act as drivers for the changes of ecosystem services. These drivers primarily involve demography, economy growth, social policies, culture, religion as well as science and technology (MA, 2005; Nelson et al., 2005). Drivers induce pressures, which directly affect ecological integrity and furthermore, influence ecosystems' generation of services (Hou et al., 2014) . Pressures often relate to land use changes, agriculture production activities and industrial activities (Alcamo et al., 2005; Bastian, 2013; Nelson et al., 2005). Apart from the impacts caused by drivers and pressures, the response, which relates to social political influences, e.g., governmental regulations, can play a positive role in preserving ecological integrity and enhancing the supply of ecosystem services (Couch and Karecha, 2006; Nuissl and Rink, 2005; Schwarz et al., 2011). Owing to the encouraging role in addressing human-environment interactions, ecosystem services approach is promising in assisting decision-making processes of local and regional environmental management (de Groot et al., 2010; Polasky et al., 2011; TEEB, 2010).

\subsection{Ecosystem services and socioeconomic gradients in urban-rural areas}

Urban-rural areas have received increasing concerns from ecosystem service investigators due to the accompanying intensive human-environment interactions (Kroll et al., 2012; Radford and James, 2013). Among the associated surveys, the ones performed in European urban-rural areas constitute a primary part (e.g., Larondelle and Haase, 2013). These investigations involve food provisioning, regulating services such as local and global climate regulation, pollination as well as recreation (Haase et al., 2012; Larondelle and Haase, 2013; Lautenbach et al., 2011; Radford and James, 2013; Schwarz et al., 2011; Strohbach and Haase, 2012). A German research group has conducted comprehensive surveys of ecosystem services in Leipzig urban-rural gradient in eastern Germany. These surveys mainly relate to the issues such as ecosystem services synergies and trade-offs (Haase et al., 2012; Larondelle and Haase, 2013), ecosystem services value transfer (Strohbach and Haase, 2012), ecosystem services' historical changes as well as the sensitivity and robustness of the evaluation results (Lautenbach et al., 2011).

The principle of urban-rural gradients was initially proposed to delineate the features of urbanization (McDonnell and Pickett, 1990). These characteristics primarily involve land cover structures, the biota of urban-rural area and socioeconomic dimensions (Hahs and McDonnell, 2006; McDonnell and Pickett, 1990). Based on the assessments of ecosystem services, some scientists further sketched urbanrural gradients of ecosystem services. The results concerning different provisioning, regulating and cultural services paint such a picture: Some services, such as food and water supply (Kroll et al., 2012), aesthetic services as well as spiritual services (Radford and James, 2013), present an increasing trend along the urban-rural gradient in the associated study areas. Others such as above ground carbon storage or sequestration (Larondelle and Haase, 2013; Radford and James, 2013; Strohbach and Haase, 2012), energy supply (Kroll et al., 2012), water flow regulation, pollination potential as well as recreation (Radford and James, 2013), show fluctuations from city center to fringe. Noticeably, although apparent ecosystem services gradients have been found in different urban-rural areas, typical models of ecosystem services gradients are evidenced not to be existing in different cities (Larondelle and Haase, 2013). 
The issue of socioeconomic gradients in urbanrural areas has gained a growing popularity, not only in social science community, but also in some interdisciplinary subjects including environmental science (Dow, 2000; McDonnell and Hahs, 2008). Kroll and Kabisch (2012) and Kroll and Müller (2011) depicted the spatial gradients of human dimensions in urban-rural landscapes in several agglomerations in Europe (see Piorr et al., 2011). These human aspects primarily refer to population density, urban fabric, dwelling area, sealed surface, employment state, mean age as well as household size. The findings suggest the suitability of the gradient approach to delineate and understand the structural differences between urban areas and the surrounding environment. Another study performed in Australia reveals the demographic and employment gradients in urban-rural gradients in Melbourne (Hahs and McDonnell, 2006). In addition to the gradients of objective socioeconomic states, the gradient of subjective well-being expressed as "happiness" was explored in the US. This survey presents a rising trend of happiness from large central cities to small towns or the rural periphery (Berry and Okulicz-Kozaryn, 2011).

The literature investigation shows that ecosystem services and socioeconomic gradients in urban-rural areas have been drawing increasing concerns from interdisciplinary scientists as these two approaches can uncover human-environmental interactions in urban-rural space. Whereas, studies on these two issues are still limited. Furthermore, we found little literature investigating the linkages between the two issues. These shortages diminish the ability of scientists to understand how human and environmental systems are interplaying in urbanrural areas.

Consequently, our research aimed at bridging the revealed gap by spatially explicitly and quantitatively characterizing urban-rural gradients of ecosystem services and socioeconomics and exploring their mutual linkages. Accordingly, we propose the following three research questions:

1) What are the spatial and quantitative characteristics of ecosystem service and socioeconomic gradients in the investigated urban-rural areas?
2) What are the similarities and differences of ecosystem service and socioeconomic gradients between different gradient patterns of distinct areas?

3) Are there linkages between ecosystem service and socioeconomic gradients in urban-rural areas?

In order to answer these questions, we performed empirical studies in the urban-rural areas of two cities, Leipzig, Germany, and Kunming, China. The former is a representative of the cities in the east of Germany witnessing their reurbanization, while the latter can be understood as a proxy of the cities in the southwest of China experiencing rapid urbanization. These two research areas are both facing intensive human-environmental interactions.

\section{Research areas}

\subsection{Leipzig urban-rural area}

The research area is situated in Eastern Germany, covering Leipzig city and the adjacent municipalities. It is a circular area with the center of Leipzig city as the centroid and a radius of 25 kilometers. The primary land covers of the entire research area are artificial areas, agricultural land, forests as well as semi-natural areas (Figure 1). Located in a temperate transition zone, Leipzig has an oceanic-continental climate with an average annual temperature and precipitation of $8.8{ }^{\circ} \mathrm{C}$ and $511 \mathrm{~mm}$, respectively (Leipzig Amt für Statistik und Wahlen, 2009). Leipzig covers large areas of commercial and industrial land, and is surrounded by intensively cultivated land. Eight percent of Leipzig is covered by green space and seven percent by forest (Leipzig Amt für Statistik und Wahlen, 2009).

Leipzig has a population of approximately 520,000 in 63 urban districts covering an area of $297 \mathrm{~km}^{2}$ (Leipzig Amt für Statistik und Wahlen, 2009). The densest population can be found in the districts with prefabricated multi-story housing estates. Surrounding the city are the municipalities of low density incorporated into Leipzig since 1999. 
Leipzig's population dropped by $12 \%$ between 1990 and 2000 due to suburbanization and out-migration, but grew by $2.7 \%$ between 2000 and 2006 (Saxon Office of Statistics, 2010). Historically, Leipzig was a center of commerce and trade. Lignite mining and chemical industry constituted the two primary economic sectors from the 19th century to the
German reunification in 1990. After the German reunification, the economy of Leipzig recessed facing national and international competition. Throughout these years new developments tentatively emerged in the service sector and in fields such as education, transportation and tourism (Haase et al., 2012).



Figure 1: Land cover map of the Leipzig urban-rural area for 2006 . The five primary classes are aggregated from Corine land cover classes (German Federal Environmental Agency, 2014). The circle area, sector 1 and sector 2 are the investigation areas with the city center of Leipzig in the centers and radiuses of 25 kilometers for gradient analysis

\subsection{Kunming urban-rural area}

Kunming is the capital of Yunnan province in Southwestern China (Figure 2). This research area consists of six districts within the Kunming region: Wuhua, Panlong, Guandu, Xishan, Chenggong and Jinning. Kunming is surrounded by mountains in the north, east and west and connected with the Dianchi Lake in the southern direction. It is situated at an elevation of around $1890 \mathrm{~m}$ on the Yunnan-Guizhou
Plateau. Kunming has a subtropical, mild highland climate throughout the whole year with humid summers and dry winters. The mean annual precipitation and mean annual temperature are $1000 \mathrm{~mm}$ and $15{ }^{\circ} \mathrm{C}$, respectively (Statistics Bureau of Kunming, 2011). The entire study area covers $4076.30 \mathrm{~km}^{2}$ including Kunming city with an area of $212 \mathrm{~km}^{2}$. The primary land covers of this area are urban and rural residential areas, cropland in the southeast of the city and in the 
east and south of the Dianchi Lake, water bodies virtually consisting of the Dianchi Lake as well as forests mainly covering the peripheral mountains (Figure 2).

The research area has a population of 3,870,000 with 3,000,000 belonging to Kunming city (Statistics Bureau of Kunming, 2011). Kunming has experienced rapid economic growth and urbanization during the last two decades. The gross domestic product (GDP) increased from 16.9 billion RMB Yuan in 1992 to 63.6 billion in 2000. From 2000 to 2010, the GDP more than tripled, reaching 212 billion RMB Yuan (Statistics Bureau of Kunming, 2011). The urbanization process of Kunming city had caused a great loss of green space in the suburban areas and an expansion of urbanized area from $184.4 \mathrm{~km}^{2}$ in 1992 to $275 \mathrm{~km}^{2}$ in 2010 (National Bureau of Statistics of China, 2011).

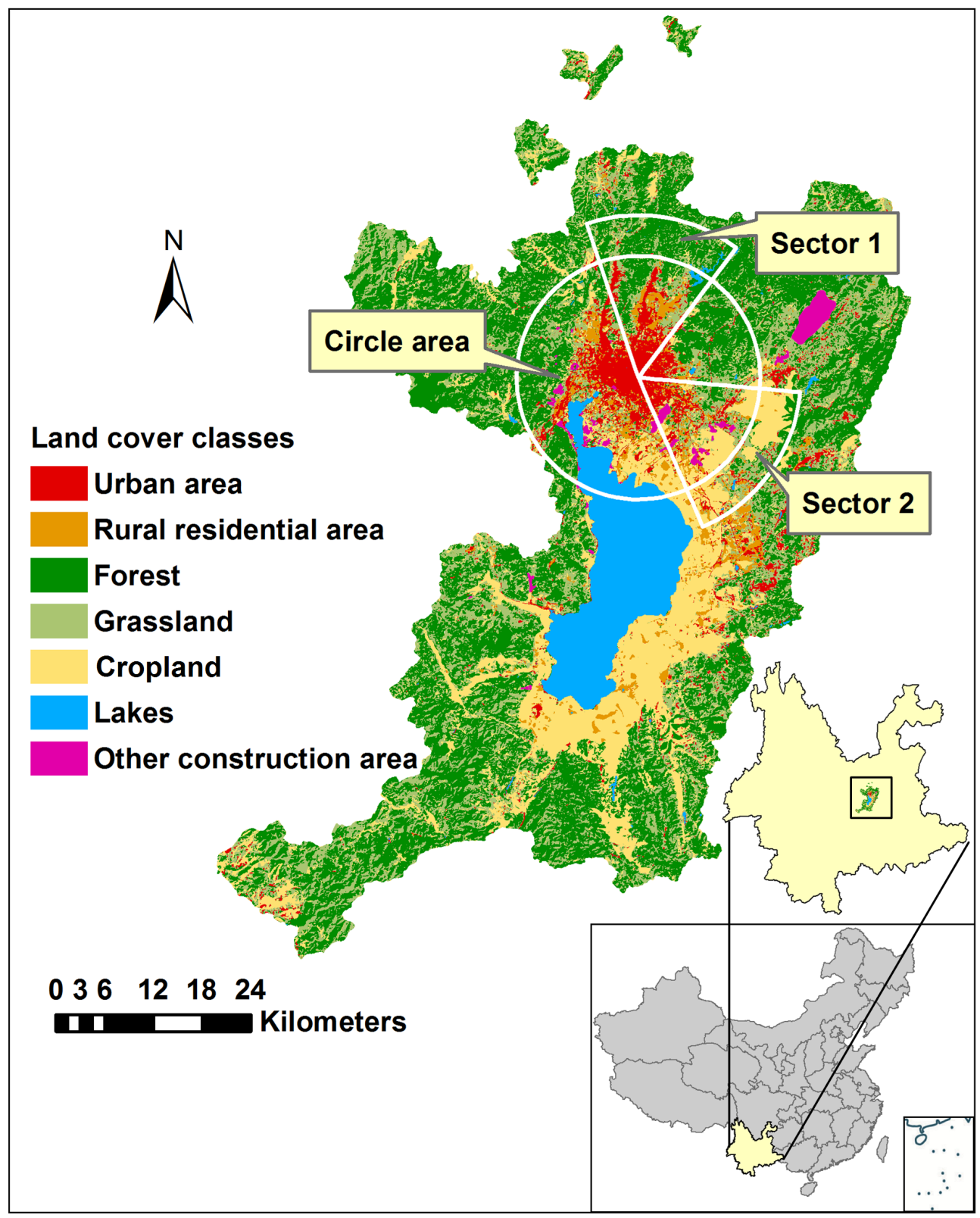

Figure 2: Land cover map of the Kunming urban-rural area for 2010. The seven primary classes have been aggregated from the classes of the National Land Classification (applicable in transitional period) released by the Ministry of Land and Resources of China in 2002 . The circle area with a radius of 15 kilometers and sectors 1 and 2 with radiuses of 20 kilometers are the areas for gradient analysis 


\section{Methods and data sources}

\subsection{Data sources}

In this research we mainly used biophysical data (land cover, climate, soil, etc.) and socioeconomic statistical and spatial data (see Table 4 and Table 5 in the appendix for the data, time span, scales and sources). The data were derived from associated regional or national governmental agencies through online or offline accessibilities, online open access data sources of scientific institutions and published work.

\subsection{Urban-rural gradient analysis}

The gradient approach is proven to be promising in revealing the spatial variations of environmental states, ecosystem processes and functions as well as socioeconomic characteristics in urban-rural areas (Kroll and Müller, 2011; McDonnell et al., 1997; McDonnell and Hahs, 2008; McDonnell and Pickett, 1990; Pouyat and McDonnel, 1991). These delineations can be either qualitative or quantitative (Kroll and Müller, 2011; McDonnell and Pickett, 1990). Moreover, the changes can be explicitly visualized by combining GIS methods with the urban-rural gradient approach (Kroll et al., 2012; Larondelle and Haase, 2013). So far, two mainstreaming gradient patterns have been developed and applied. One is concentric ring gradients dispersing from the city center to rural outskirts (Kroll et al., 2012); the other one is transect gradient directionally crossing the city center and extending to rural areas with its two ends (Hahs and McDonnell, 2006; Zhou and Wang, 2011).

In this study, we used the concentric ring gradient method reported by Kroll et al. (2012) to spatially and quantitatively describe the distributions and variations of ecosystem services and socioeconomics of the research areas. Additionally, we modified this type of gradient and developed concentric sector ring gradients which can detailedly sketch specific sectors of the total circle area. For the Leipzig urbanrural area we created three concentric buffers to investigate gradients. One is a $25-\mathrm{km}$ concentric ring area with 1-km intervals spreading out from the Leipzig city center. The other two are two concentric sector ring areas with the same radius and intervals dispersing from the city center to the south and east, respectively (Figure 1). For the Kunming urbanrural area also three concentric gradients with 1-km intervals were created including a circle area and two sector areas. All starting from the Kunming city center, the circle area extends $15 \mathrm{~km}$ and the two sectors disperse to the north and southeast with radiuses of $20 \mathrm{~km}$ (Figure 2). When selecting the respective two concentric sector ring areas of the two study areas, we considered that the two sectors can capture the areas with apparently different land use structure and distribution compared to the rest of the entire circle area.

Land covers have significant impact on ecosystem service supplies and the urban-rural distributions of socioeconomic elements (Burkhard et al., 2014; Jenerette et al., 2007; Luck et al., 2009). In this study land cover gradients were quantified and shown by area proportions of different land cover classes in each rings of all the gradient areas of the two study areas. With these results, we can to some extent explain the gradient characteristics of ecosystem services and socioeconomics.

In this study we used GIS techniques to delineate the features of several ecosystem services and socioeconomic dimensions across the urban-rural space in the two case study areas. Quantitative changes of the gradients were further shown with the average values of each ecosystem service and socioeconomic indicators for each concentric ring area. The findings in the forms of maps and line charts are given in the results section. Considering the uncertainty propagation with spatial aggregation and value averaging (Hou et al., 2013), we quantified the uncertainties in the calculations of selected indicators. The findings shown in the discussion section can provide insights into the magnitudes and variation trends of uncertainties along the urbanrural gradients of the two research areas. 


\subsection{Indicator selections, calculations and gradient creations}

Ecosystem services indicators can be proxies of different ecosystem service types. Calculating the indicators or measuring the values is a mainstreaming approach to quantify ecosystem services (Müller and Burkhard, 2012). Appropriate ecosystem service indicators should be quantifiable, sensitive to land cover changes, spatially and temporally explicit and scalable(Burkhard etal., 2012). The ecosystem service indicators chosen in this study are highly sensitive to land cover changes, so their spatial variation in the considerably dynamic urban-rural environments can be efficiently captured. Additionally, we based the selections of the indicators on their typicality in the two study areas, the comparability between the two research areas and data availability. Thereafter, three regulating and two provisioning service indicators, which are habitat quality, above ground carbon storage, f-evapotranspiration, food supply and energy supply were selected for Leipzig urban-rural area. For Kunming urban-rural area, two regulating service and one provisioning service indicators were selected. They are habitat quality, net primary productivity (NPP) and food productivity. The indicators were calculated by robust methods from published literature, or based on empirical or statistical data (see Table 1 for the detailed information on the indicators).

Demonstrating the intensity and extensity of socioeconomic activities requires appropriate indicators which are sensitive to socioeconomic

Table 1: Overview of the quantified ecosystem service an socioeconomic indicators and the calculation methods

\begin{tabular}{|c|c|c|c|c|}
\hline Study areas & Indicators & Units & Quantification methods & Data sources and references \\
\hline \multirow{5}{*}{$\begin{array}{l}\text { Leipzig } \\
\text { ecosystem } \\
\text { services }\end{array}$} & Habitat quality & relative value & InVEST biodiversity model & Tallis et al., 2013 \\
\hline & $\begin{array}{l}\text { Above ground } \\
\text { carbon storage }\end{array}$ & $\mathrm{MgC} / \mathrm{ha}$ & $\begin{array}{l}\text { Look-up table with above ground carbon storage per land cover } \\
\text { type }\end{array}$ & Larondelle and Haase, 2013 \\
\hline & f-evapotranspiration & relative value & Look-up table with $\mathrm{f}$-evapotranspiration value per land cover type & Larondelle and Haase, 2013 \\
\hline & Food supply & GJ/ha & Regression model for land cover and soil types (yield) & Kroll et al., 2012 \\
\hline & Energy supply & $\mathrm{GJ} / \mathrm{ha}$ & $\begin{array}{l}\text { Assignation of energy supplies of different energy types to } \\
\text { associated land cover classes }\end{array}$ & Kroll et al., 2012 \\
\hline \multirow{6}{*}{$\begin{array}{l}\text { Leipzig } \\
\text { socioeconomics }\end{array}$} & Road density & $\mathrm{km} / \mathrm{km}^{2}$ & Road length divided by area of the associated ring & See data sources in Table 4 in the appendix \\
\hline & Urban fabric & $\%$ & Urban fabric area divided by total area of the associated ring & See data sources in Table 4 in the appendix \\
\hline & Population density & persons $/ \mathrm{km}^{2}$ & Leipzig municipality and city district population statistical data & See data sources in Table 4 in the appendix \\
\hline & Household size & $\begin{array}{l}\text { persons/house- } \\
\text { hold }\end{array}$ & Leipzig municipality and city district population statistical data & See data sources in Table 4 in the appendix \\
\hline & Housing area & $\mathrm{m}^{2} /$ person & Leipzig municipality and city district population statistical data & See data sources in Table 4 in the appendix \\
\hline & Unemployment rate & $\%$ & Leipzig municipality and city district population statistical data & See data sources in Table 4 in the appendix \\
\hline \multirow{3}{*}{$\begin{array}{l}\text { Kunming } \\
\text { ecosystem } \\
\text { services }\end{array}$} & Habitat quality & relative value & InVEST biodiversity model & Tallis et al., 2013 \\
\hline & NPP & $\mathrm{gC} / \mathrm{m}^{2} / \mathrm{yr}$ & MODIS GPP/NPP Project (MOD17) & $\begin{array}{l}\text { Numerical Terradynamic Simulation } \\
\text { Group, 2013; Lin et al., 2008; Sun et al., } \\
\text { 2011; Chinnaiah and Madhu, } 2010\end{array}$ \\
\hline & Food productivity & yuan $/ \mathrm{km}^{2}$ & $\begin{array}{l}\text { Assignation of food outputs of different food type to associated } \\
\text { land cover classes }\end{array}$ & $\begin{array}{l}\text { See data sources in } \\
\text { Table } 5 \text { in the appendix }\end{array}$ \\
\hline \multirow[t]{3}{*}{$\begin{array}{l}\text { Kunming } \\
\text { socioeconomics }\end{array}$} & Road density & $\mathrm{km} / \mathrm{km}^{2}$ & Road length divided by area of the associated ring & $\begin{array}{l}\text { See data sources in } \\
\text { Table } 5 \text { in the appendix }\end{array}$ \\
\hline & Urban fabric & $\%$ & Urban fabric area divided by total area of the associated ring & See data sources in \\
\hline & Population density & persons $/ \mathrm{km}^{2}$ & Kunming districts and counties population statistical data & $\begin{array}{l}\text { Table } 5 \text { in the appendix } \\
\text { See data sources in } \\
\text { Table } 5 \text { in the appendix }\end{array}$ \\
\hline
\end{tabular}


spatial and temporal dynamics. In this study we chose indicators involving the three primary human dimensions of urban-rural system: artificial environment, socio-demography and economy (Kroll and Müller, 2011). The calculations of the indicators were based on simple formulas with statistical or spatial data (Table 1).

\section{Ecosystem service indicators}

\section{Habitat quality}

Habitat quality is a proxy of land's biodiversity support capability. It involves the capability of the ecosystem to provide conditions appropriate for individual and population persistence (Tallis et al., 2013). Habitat quality modeling can be an acceptable solution to reflect the overall potential of regional biodiversity. One novel and promising modeling tool is the InVEST biodiversity model, which combines information on LULC and threats to biodiversity to produce habitat quality maps (Tallis et al., 2013). For the details of the model, see the InVEST 2.5.5 User's Guide (Tallis et al., 2013).

This study employed the InVEST biodiversity model to quantify and visualize the habitat qualities of the two study areas. For the Leipzig urban-rural area, we used the Corine land cover spatial data of 2006 as the current land cover map and considered cropland, urban area, roads and railways as biodiversity threats. For the Kunming urban-rural area, a land cover map rasterized from a 1:100,000 shapefile map of 2010 was used and cropland, urban and rural residential area, construction area as well as roads were assigned as threats. The two biophysical tables of each study area were adapted from the sample data of the InVEST biodiversity model with changes based on the land cover classifications of the associated study area. The derived habitat quality raster maps were converted to polypoint shapefiles in order to calculate the average values of the concentric rings of the circle and sector areas. Based on this, the habitat quality gradients were generated in the form of line charts. The modeling results are relative values between 0 and 1. Areas with higher values on the habitat quality maps enjoy better habitat quality compared to the rest of landscape. It is important to note that the habitat quality values of Leipzig and Kunming are not comparable as the model parameter inputs (e.g., the biophysical tables) were different from each other.

\section{Above ground carbon storage}

Being an important part of the global carbon cycle, terrestrial carbon storage consists of four layers: above ground biomass, deadwood and litters, below ground biomass and soil carbon storage. It is difficult to completely count the carbon storage of the four layers in terrestrial ecosystems. Whereas, measuring and estimating above ground carbon storage is feasible, and the results are credible (Haase et al., 2012; Strohbach and Haase, 2012). In this study the indicator "above ground carbon storage" was chosen to represent urban-rural ecosystems' global climate regulation services. As above ground biomass is sensitive to land cover types, estimating above ground carbon storage of different land cover classes can reveal the spatial dynamics of contributions from urban-rural ecosystems to mitigate climate change.

In this study, empirical values from research proceeded in Leipzig city were used to calculate this indicator (Larondelle and Haase, 2013; Strohbach and Haase, 2012). Above ground carbon storage values of different Corine land cover classes were derived by transferring the measured above ground carbon stock of the trees in the urban-rural gradient of Leipzig (Larondelle and Haase, 2013). By linking the empirical values to the associated land covers, we mapped the spatial distributions of the above ground carbon storage of the Leipzig urban-rural area. Furthermore, the quantitative changes of this service along the urban-rural gradient were characterized by plotting the average values of each concentric ring of the circle and the two sector areas.

\section{Net primary production (NPP)}

NPP represents the net carbon uptake from the atmosphere into biosphere. It is widely used to evaluate the patterns, processes and dynamics of carbon cycling in ecosystems, assess ecosystem status and monitor environmental changes (Ingraham and Foster, 2008; Melillo et al., 1993; Zhao and Zhou, 2005). Given the role NPP plays in carbon cycling, this study uses it to indicate the global climate regulation service of Kunming urban-rural area. 
We distinguished the NPP quantification into three methods based on different data sources and existing research. For vegetation NPP, the MOD17A3 NPP product produced by the Numerical Terradynamic Simulation Group of the University of Montana was used (see Table 5 in the appendix for data sources). The NPP value of urban area was transferred from Lin et al. (2008). The NPP of the Dianchi Lake was assessed with reference to Sun et al. (2011) and Chinnaiah and Madhu (2010).

The MOD17A3 NPP product is generated from NASA MODIS data by the Numerical Terradynamic Simulation Group. It provides continuous estimates of NPP across the earth's entire vegetated land surface. For this research we used the annual global NPP of 2006 and extracted the Kunming urban-rural area from the global map. Lin et al. (2008) estimated the NPP of the urban area of Shanghai, China based on urban forest inventory data of 2006 and remote sensing. Considering the similarities of the climates between Kunming and Shanghai, we transferred the NPP value of Shanghai city from Lin et al. (2008) to the Kunming urban area. Sun et al. (2011) measured the surface water gross primary production (GPP) of the north, middle and south of the Dianchi Lake from the winter of 2009 to the spring of 2010. Chinnaiah and Madhu (2010) estimated the NPP/ GPP ratio from October 2009 to September 2010 for the Darmasagar Lake in India. This study adapted the findings of these two studies to estimate the NPP values for the parts of the Dianchi Lake that belong to the six districts of the research area. For the calculation, the GPP values of spring from Sun et al. (2011) were used to calculate the annual average GPP of the Dianchi Lake. The mean NPP/GPP ratio from Chinnaiah and Madhu (2010) was used to convert GPP to NPP.

By joining the NPP derived from the above described methods using the union tool of ArcGIS 10, we produced the NPP map for the entire Kunming urbanrural area. Furthermore, the map was resampled to grids of $200 \mathrm{~m} \times 200 \mathrm{~m}$ and intersected with the concentric rings of the circle and two sector areas. Thereafter, the Kunming urban-rural gradients of NPP was generated by averaging the values in each concentric ring and shown by line chart in the result section of this article.

\section{f-evapotranspiration}

Evapotranspiration plays a significant role in regulating local temperature, humidity and precipitation. Therefore, it is usually employed to indicate ecosystem's capacity to regulate local climate (Burkhard et al., 2009; Kandziora et al., 2013; Schwarz et al., 2011).

In this study "f-evapotranspiration" was used as a local climate regulation service indicator. Referring to latent heat flows, f-evapotranspiration is an approximation for the evapotranspiration potential of a land cover class (Schwarz et al., 2011). According to Schwarz et al. (2011), f-evapotransipiration is calculated with the following formula:

$$
f(i)=\frac{\max \text { evapotranspiration }(i)}{E T_{(0)}}
$$

Here ${ }_{\max }$ evapotranspiration(i) is the maximal evapotranspiration of land cover type $i$, and $E T_{(0)}$ is the reference evapotranspiration of the grass of $12 \mathrm{~mm}$ high in the local climate.

The f-evapotranspiration values of different Corine land cover classes were derived from a lookup table after Larondelle and Haase (2013). These values were transferred from the calculation and estimation (Schwarz et al., 2011) in the Leipzig urbanrural area. By linking the empirical values to the associated land covers, we showed the distribution of $f$-evapotranspiration across Leipzig urban-rural area. The quantitative dynamics of this service along the gradient were further presented by a line chart with the average values of each concentric ring of the circle and two sector areas.

\section{Food supply and food productivity}

As one of the basic ecosystem goods, food is a fundamental material input of urban systems and crucial for the survival of the urban population (Jansson and Polasky, 2010). In this study we employed food supply and food productivity to indicate the food provisioning services of Leipzig and Kunming urban-rural areas, respectively. For the details of the calculation of food supply, see Kroll et al. (2012). 
The food productivity of the Kunming urban-rural area was computed in RMB yuan $/ \mathrm{km}^{2}$ for each land cover type of the six districts. Statistical data of 2010 on crop types and outputs (cereals, oil crops, cane, tobacco, vegetables fruits, nuts, spices and Chinese herbal medicine), sheep and caws, poultries as well as aquaculture products of different districts were used to calculate the average values of food output per $\mathrm{km}^{2}$ (food productivity) of cropland, forest, grassland, rural residential area and lakes of the associated district (for data sources see Table 5 in the appendix). Pig production was not considered as pig farms cannot clearly be classified into a certain land cover type.

Based on the above described calculations, we linked the values of food supply and food productivity to the associated land cover types of the spatial land cover data of Leipzig and Kunming with ArcGIS, respectively. Accordingly, the maps of food provision of the Leipzig and Kunming urban-rural areas were produced. Moreover, food provision values were averaged in each concentric ring of the circle and sector areas of Leipzig and Kunming.

\section{Energy supply}

Energy is another important good natural system provides for human well-being. Although some energy sources are not regarded to be strongly linked with ecosystem processes and functions (e.g., wind energy and solar energy), they can have synergies or tradeoffs with some ecosystem services, and be considerably influential in the decision making procedures of environmental management (Burkhard et al., 2014). This study calculated the energy supply of Leipzig urban-rural area for 2007 in the unit of GJ/ha and delineated its spatial distributions and gradients (for data sources, see Table 4 in the appendix). For the details of the respective quantification methods, see Kroll et al. (2012).

\section{Socioeconomic indicators}

\section{Road density and urban fabric}

To calculate the road density of the Leipzig urbanrural area, we used road network maps of 2006 for the entire Germany and the Leipzig city district level and a railway network map of 2008 for the Leipzig city district level (see Table 4 in the appendix for data sources). For Kunming, a road network map of 2007 at the China national level was used (see Table 5 in the appendix for data sources). Then we intersected these maps with the maps of the circle and sector areas of concentric rings of Leipzig and Kunming. Based on this, we calculated the road densities of each concentric ring by dividing road length by area of the corresponding concentric ring. Urban fabric was computed in the unit of percent by dividing the urban fabric area by the total area of each concentric ring. This method was applied both to the circle and sector areas of Leipzig and Kunming. To accomplish this calculation, urban fabric maps were extracted from the land cover maps of Leipzig for 2006 and Kunming for 2010 (see Table 4 and Table 5 in the appendix for data sources).

\section{Population density, household size, housing area and unemployment rate}

Socio-demographic data from local and regional statistic offices were used to estimate the values of these four indicators of the Leipzig urban-rural area, (see Table 4 in the appendix for data sources). The calculation methods were developed and described by Kroll and Kabisch (2012).

To estimate the population density of the Kunming urban-rural area, we used the population and land cover data of the six districts constituting the research area (for data sources see Table 5 in the appendix). Urban population and rural population were assigned to urban area and rural residential area, respectively. The other five land cover classes, forest cropland, grassland, lakes and construction were assumed not to be populated. Then we calculated the population densities of the urban and rural residential areas of the six districts. Afterward a population density map was produced by joining the results with the land cover map in ArcGIS. Furthermore, we converted the map to a grid map with the cell size of $200 \mathrm{~m} \times 200 \mathrm{~m}$, intersected it this the concentric ring and concentric sector ring maps and computed the average values of each concentric ring. Finally, the population gradient line chart of Kunming urban-rural area was derived. 


\subsection{Comparisons of gradient patterns and case study areas}

In this study we compared the three gradients of the concentric ring and concentric sector ring gradient patterns in order to examine their appropriateness. The comparisons were performed with the land cover structure, each ecosystem service and socioeconomic item investigated in this study for Leipzig and Kunming urban-rural areas. To achieve this purpose, we presented the three gradients in the same line chart to reveal the mutual similarities and differences. These comparisons can on the one hand reveal the spatial heterogeneities of the compared objects and on the other hand, address the uncertainties of the concentric ring gradient pattern, which are generalized from the heterogeneous patches in the ring. Furthermore, we quantified and presented the uncertainties of the three gradients with four indicators in the discussions. The indicators are above ground carbon storage and housing area of Leipzig and habitat quality and population density of Kunming.

The two study areas of this study may exhibit different spatial dynamics and urban-rural gradients with ecosystem services and socioeconomic dimensions. These variations can be caused by their distinct physical conditions, urbanization processes and socio-political systems. To examine the applicability of the concentric ring approach in these two areas, we compared their ecosystem service and socioeconomic gradients and described the similarities and differences in the results section.

\subsection{Analysis of ecosystem service-socioeconomics gradient linkages}

Ecosystem service supply and demand in urbanrural systems are reported to be closely linked with regional human activities (Burkhard et al., 2012; Hou et al., 2014; Kroll et al., 2012). Accordingly, we assume that ecosystem service and socioeconomic gradients should correlate in the urban-rural contexts of the two research areas.

In this study we firstly observed the qualitative linkages between the investigated ecosystem services and socioeconomic items by comparing their gradients shown by the line charts. Furthermore, we quantified the correlations between ecosystem service and socioeconomic gradients applying Spearman correlation analyses between each pair of ecosystem service and socioeconomic indicators for the three concentric ring areas of the two study areas.

\section{Results}

\subsection{Land cover gradients in Leipzig and Kunming urban-rural areas}

The artificial surfaces proportions showed overall declining trends along the urban-rural gradients in the circle and the two sectors areas in Leipzig (Figure 3). Contrarily, the proportions of agriculture areas presented overall growing trends along the gradients in these three gradient areas. The gradients of these two land cover classes were less smooth in the two sector areas, especially in sector 2 , than in the circle area. The proportions of the other three land cover classes: forest and semi-natural areas, wetlands and water bodies, presented apparent irregular changes from the city center to $25 \mathrm{~km}$ away from the city center in all the three gradient areas of Leipzig.

In Kunming urban-rural area, the urban area proportions showed apparent declining trends along the gradients in the circle and the two sector areas (Figure 4). In contrast, the forest shares kept increasing along the gradients in the circle and sector 1 areas. In sector 2 , it fluctuated at low levels along the gradient. The proportions of cropland showed different trends between the circle and the two sector areas. In the circle area, it generally kept increasing along the gradient; in sector 1 , it fluctuated slightly at low levels; in sector 2, cropland share showed a first soaring then plummeting trend. The proportions of the other three land cover types: grassland, rural residential area and lakes, showed irregular changes along the urban-rural gradient in all the three gradient areas. 

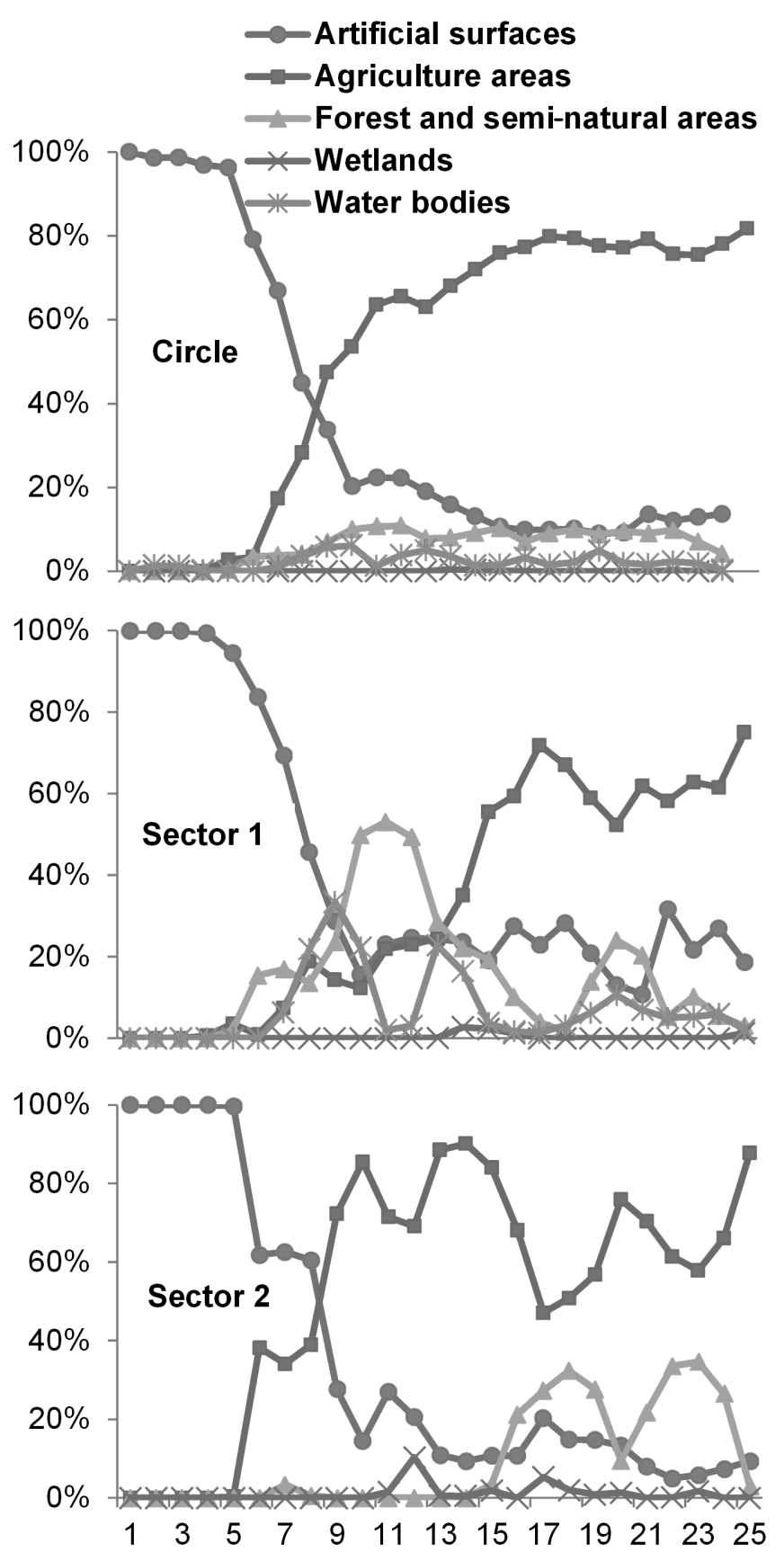

Figure 3: Land cover gradients along the Leipzig urbanrural area. The $X$-axis is the distance in kilometers from the city center of Leipzig. The Y-axis is the area proportions of different land cover classes in the total area of the associated concentric ring or concentric sector ring

\subsection{Ecosystem service and socioeconomic gradients in Leipzig urban-rural area}

All the five ecosystem services generally demonstrated an increase along the urban-rural gradient except above ground carbon storage (Figure 5).
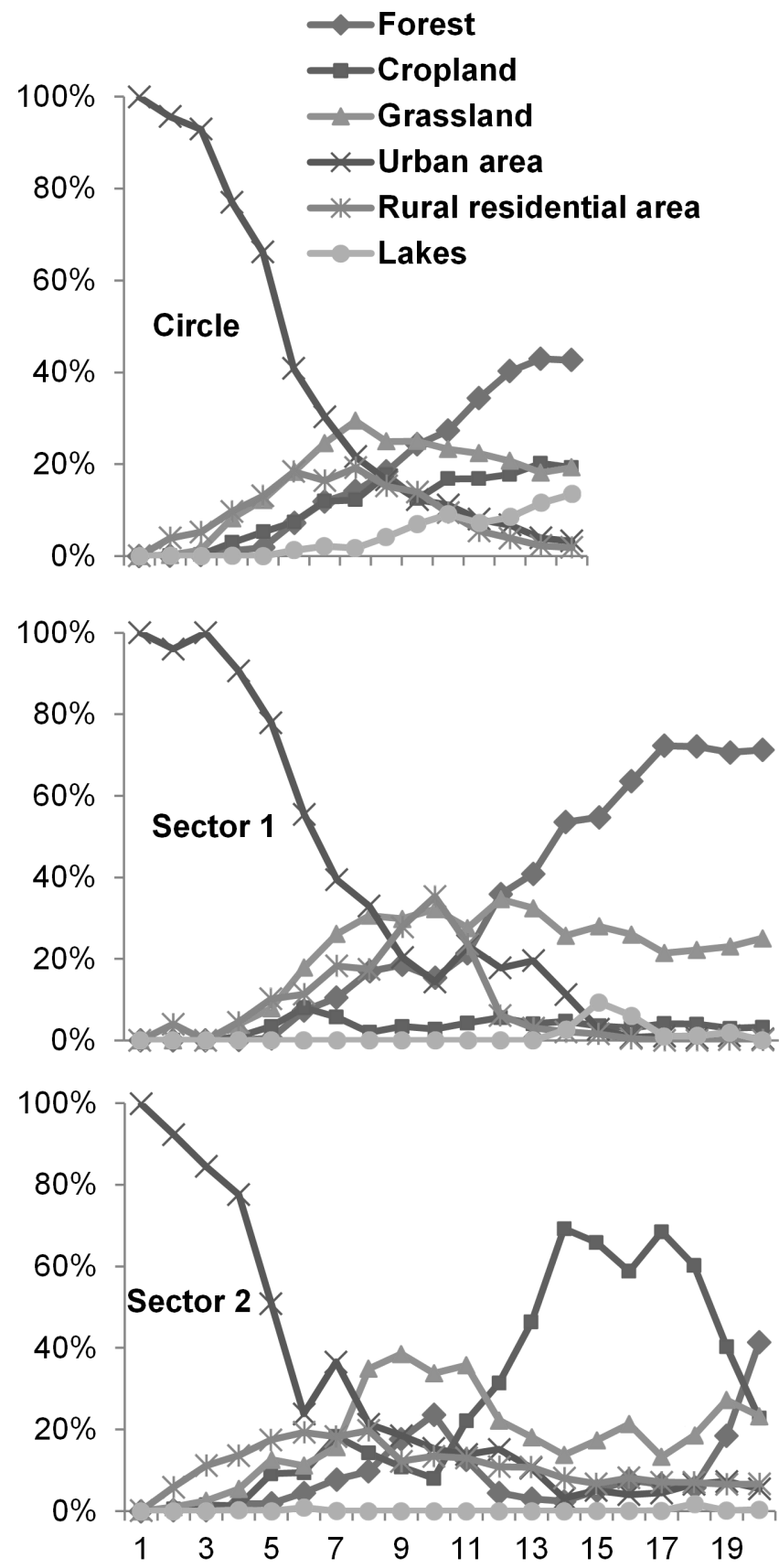

Figure 4: Land cover gradients along the Kunming urbanrural area. The $X$-axis is the distance in kilometers from the city center of Kunming. The Y-axis is the area proportions of different land cover classes in the total area of the associated concentric ring or concentric sector ring

This exception showed a reversed trend that the urban area roughly had higher above ground carbon storage than the rural area. Having said this, the urban-rural spatial variations of the five ecosystem services were not even in different parts of the circle area. For example, sector 1 revealed highly irregular 
distributions of all the five ecosystem services and sector 2 showed special irregularities with above carbon storage, food supply and energy supply.

The five ecosystem services presented gradient characteristics in different degrees in Leipzig urbanrural area (Figure 6). Habitat quality obviously kept increasing from the city center to the concentric ring
25 kilometers away in all the three investigated areas (circle, sector 1 and sector 2). It showed a smoother rising trend in the circle area than in sector 1 and sector 2. Above ground carbon storage generally declined along the urban-rural gradient of Leipzig. It is noteworthy that this service showed two sudden surges in the regions around 17 and 23 kilometers away from the city center in sector 2 .
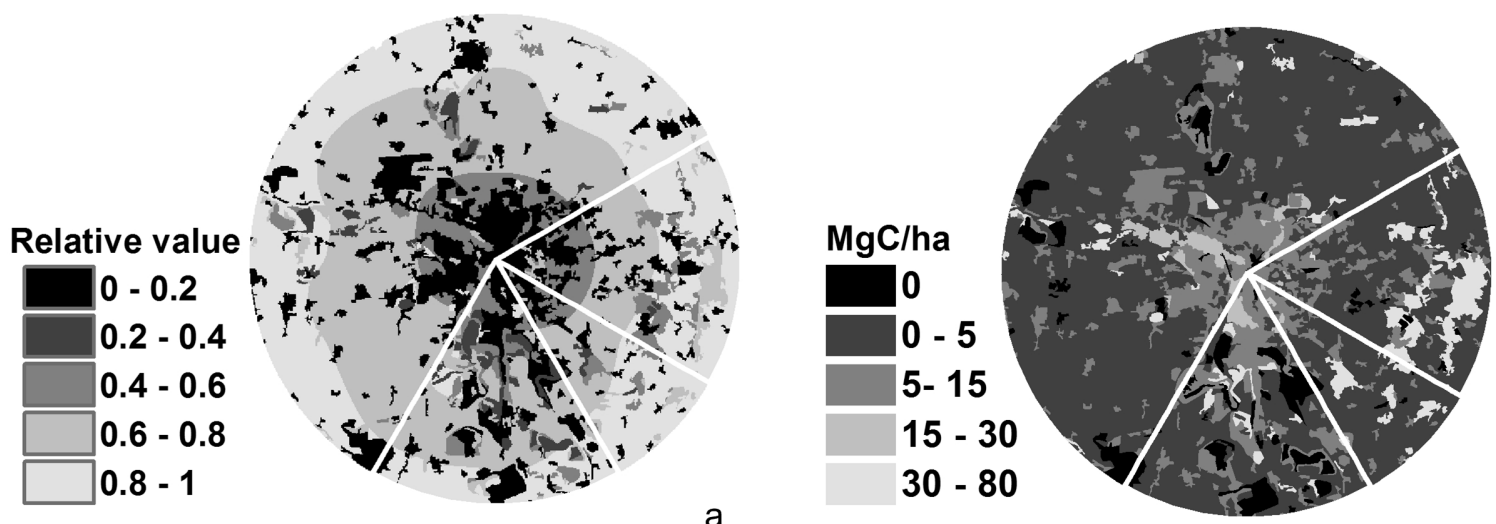

b
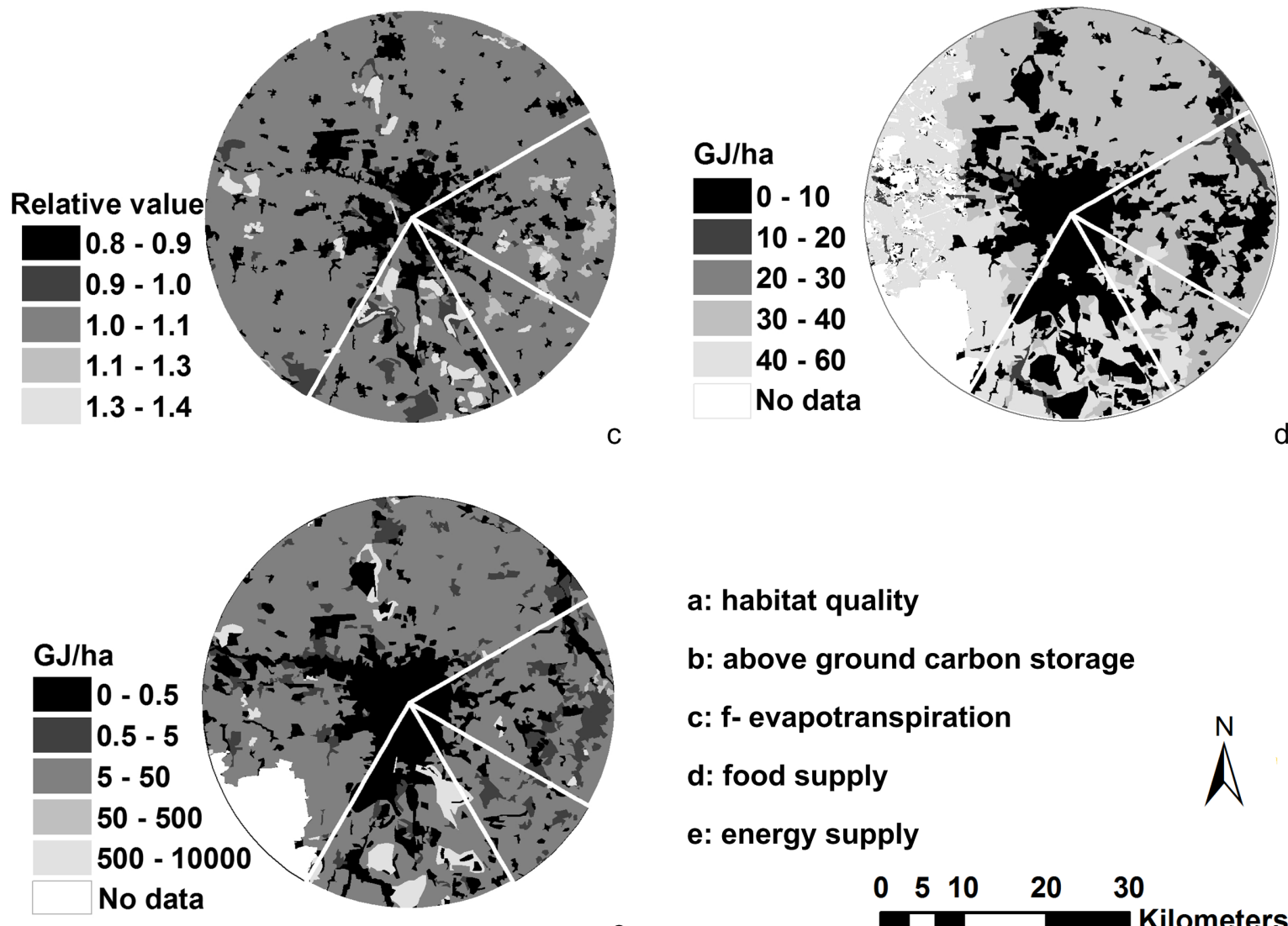

a: habitat quality

b: above ground carbon storage

c: f- evapotranspiration

d: food supply

e: energy supply

e

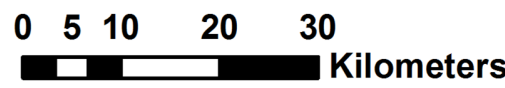

Figure 5: Spatial distributions of the five ecosystem services in the circle and sector areas of the Leipzig urban-rural gradient. a, b, c items are for 2006 and d, e items are for 2007 (d and e are adapted from Kroll et al., 2012) 

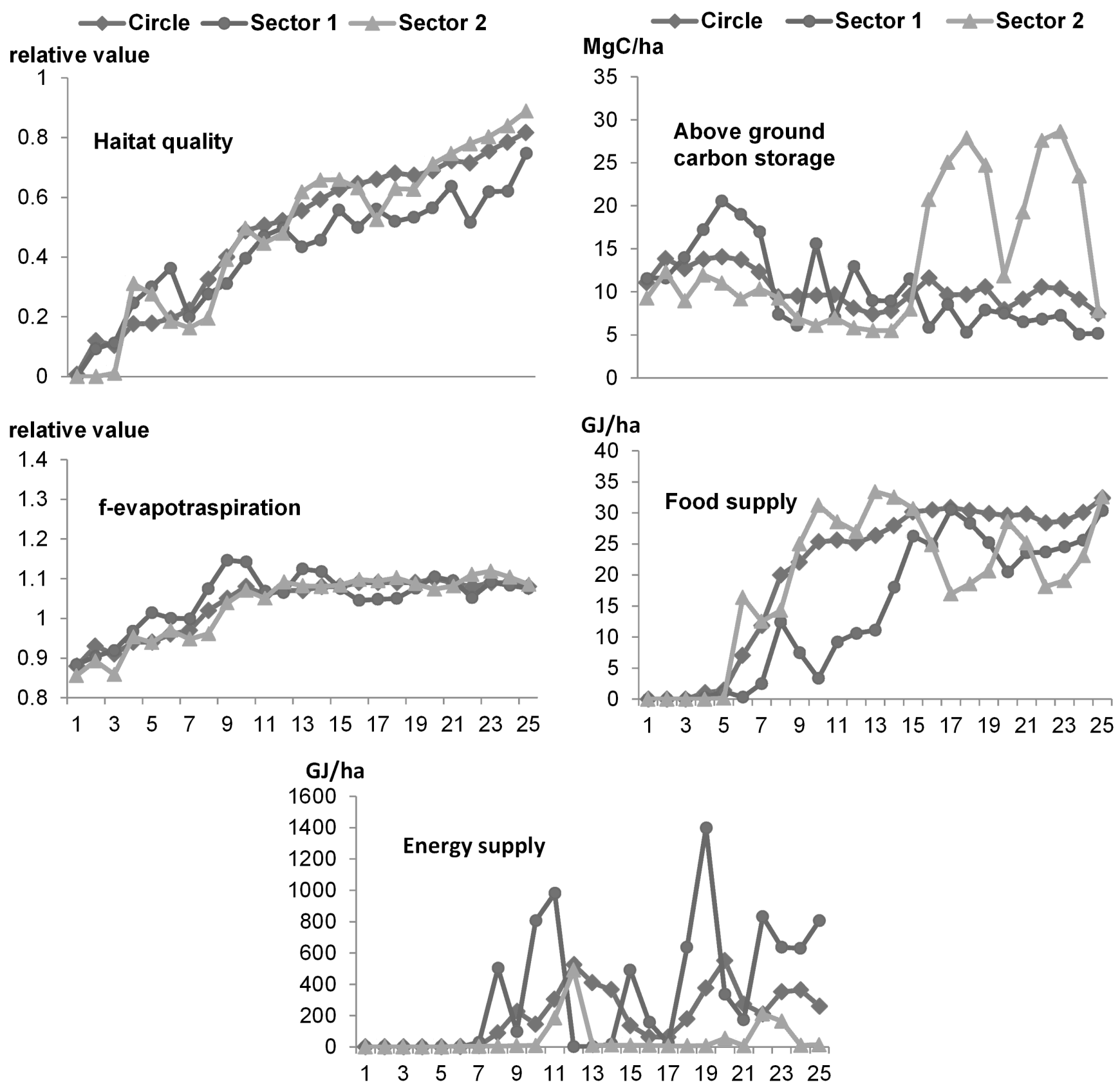

Figure 6: Gradients of the five ecosystem services in the circle and sector areas of the Leipzig urban-rural area. The $\mathrm{X}$-axis is the distance in kilometers from the city center of Leipzig. The Y-axis is the average ecosystem service value of the associated concentric ring or concentric sector ring of the circle or sectors (food supply and energy supply are adapted from Kroll et al., 2012)

The characteristic of the f-evapotranspiration gradient was similar to that of habitat quality, revealing an apparent value increase along the urban-rural gradient. Although food supply and energy supply appeared with higher values in the rural area than in the urban area, they enjoyed considerably irregular gradients than the other three services. Noteworthily, the services in the circle areas changed (increased or decreased) more smoothly than in the two sector areas for all the five ecosystem services.

All the socioeconomic gradients of the Leipzig urban-rural area were much more regular than the ecosystem service gradients (Figure 7). Among the 

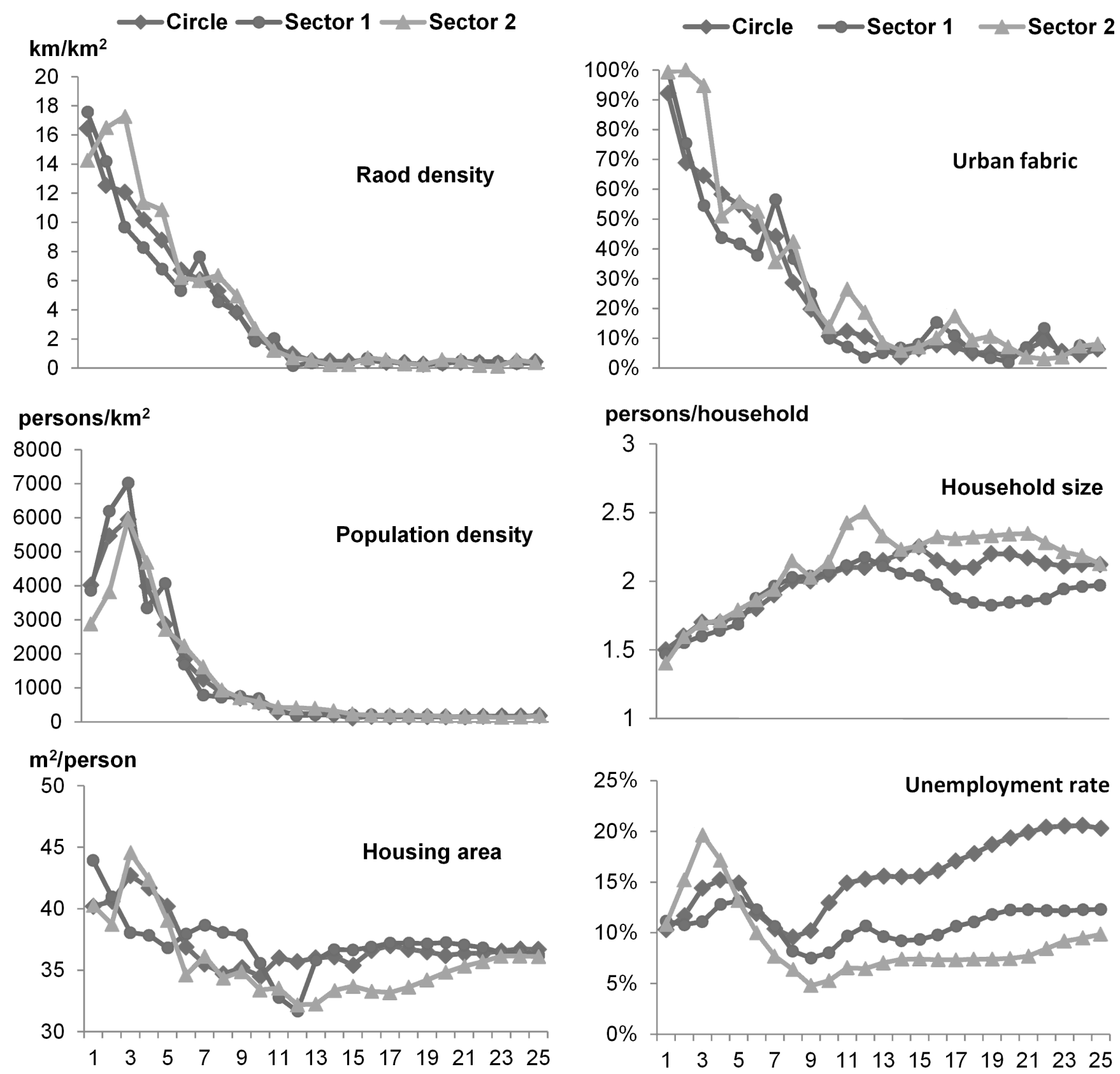

Figure 7: Gradients of the six socioeconomic items in the circle and sector areas of the Leipzig urban-rural area. The $\mathrm{X}$-axis is the distance in kilometers from the city center of Leipzig. The Y-axis is the average value of the socioeconomic indicators in the associated concentric ring or concentric sector ring of the circle or sectors. Road density and urban fabric are for 2006 and the other four indicators are for 2005 (after Kroll and Kabisch, 2012)

socioeconomic dimensions, road density and urban fabric showed generally declining trends along the gradient. Differently, population density, household size, housing area as well as unemployment rate appeared notable turning points in some concentric rings. Among them, population density reached the peak 3 kilometers away from the Leipzig city center and then kept decreasing. Household size grew to the peaks around 13 kilometers away from the city center and either remained stable or slightly decreased in the circle or the two sector areas. Housing area declined to the minimum around 12 kilometers away from the city center and then turned growing slowly. Unemployment rate experienced firstly increasing and then decreasing and finally rising trends in all the three areas. 


\subsection{Ecosystem service and socioeconomic gradients in Kunming urban-rural area}

The spatial distributions of the three ecosystem services presented consistency to some extent (Figure 8). Habitat quality appeared with an apparently increasing trend from the city center to the northern and western directions. Along the eastern and southern directions, the spatial changes of habitat quality were less regular than the other two directions. The NPP gradient was not as fine as the gradient of habitat quality, whereas, apparent spatial changes of the NPP gradient, which were similar to that of habitat quality, can be identified. With regard to food productivity, cropland area had considerably higher values than the other areas. The southern part of the Dianchi Lake had moderate values higher than the northern part of the lake and most of the forest, urban and grassland areas. The five branch-shaped areas can be even more clearly seen. However, different from habitat quality and NPP, these five branches areas had higher values than the surrounding areas.

The three ecosystem services had apparent gradient characteristics in the three gradient areas (the circle and two sectors, Figure 9). Habitat quality virtually kept increasing along the urban-rural gradient in all the three areas. Among them the growing line in the circle area was smoother than the two sectors'. NPP in the circle area monotonically rose from about 300 $\mathrm{gC} / \mathrm{m}^{2} / \mathrm{yr}$ in the city center to nearly $900 \mathrm{gC} / \mathrm{m}^{2} / \mathrm{yr}$ in the concentric ring 15 kilometers away from the city center. In the two sectors, NPP appeared roughly growing trends. The food productivity gradients showed noticeable divergences in the three areas. In the circle area, food productivity appeared with a generally growing trend with trivial fluctuations. In sector 1 it remained below $100 \times 10^{4}$ yuan $/ \mathrm{km}^{2}$ all along the gradient; in sector 2, it fluctuated significantly along the urban-rural gradient.

The three socioeconomic dimensions also showed noticeable gradient features (Figure 8 and 9). All the three socioeconomic dimensions showed apparent high densities in the urban area and reductions in the areas spreading out from the city center. In addition, they extended to the southeast of the urban area and were distributed between the
Dianchi Lake and the mountainous area in the east in moderate densities. Notably decreasing trends of the three socioeconomic indicators' values can be found along the urban-rural gradients in the circle and the 2 sector areas. Road density monotonically kept reducing along the urban-rural gradient in all the three investigated areas. Urban fabric quickly dropped from $100 \%$ at the city center to nearly $0 \%$ at the end of the gradient. Moreover, population density showed identical gradients in the three areas decreasing from 20,000 persons $/ \mathrm{km}^{2}$ to nearly zero. The differences from urban fabric and population density to road density were the several slight fluctuations in sector 2 .

\subsection{Gradient comparisons between Leipzig and Kunming}

Notable similarities and differences emerge when ecosystem service gradients are compared between the urban-rural areas of Leipzig and Kunming. With regard to habitat quality, both research areas enjoyed marked increases along the gradients in the circle and sector areas. The most significant difference was the much smoother changing trends of habitat quality in the three investigated areas of Kunming compared to that of Leipzig. Another comparison can be found between above ground carbon storage of Leipzig urban-rural area and NPP of Kunming. Although these two indicators both relate to ecosystem's production function based on photosynthesis and can in some degree represent global climate regulation service, they demonstrated different gradient characteristics. As described in the preceding sections, above ground carbon storage roughly declined along the urbanrural gradient in the circle and sector 1 areas of Leipzig, despite of some fluctuations. Contrarily, NPP showed noticeably growing trends along the urban-rural gradients in the circle and sector 1 areas of Kunming. Food provisioning services of the two research areas showed similar variations along some gradient patterns and different spatial dynamics along others. In the circle area of Leipzig, food supply appeared with a firstly increasing and then stable trend. This phenomenon was similar to that of food productivity in the circle area of Kunming. However, food productivity in sector 1 of Kunming 


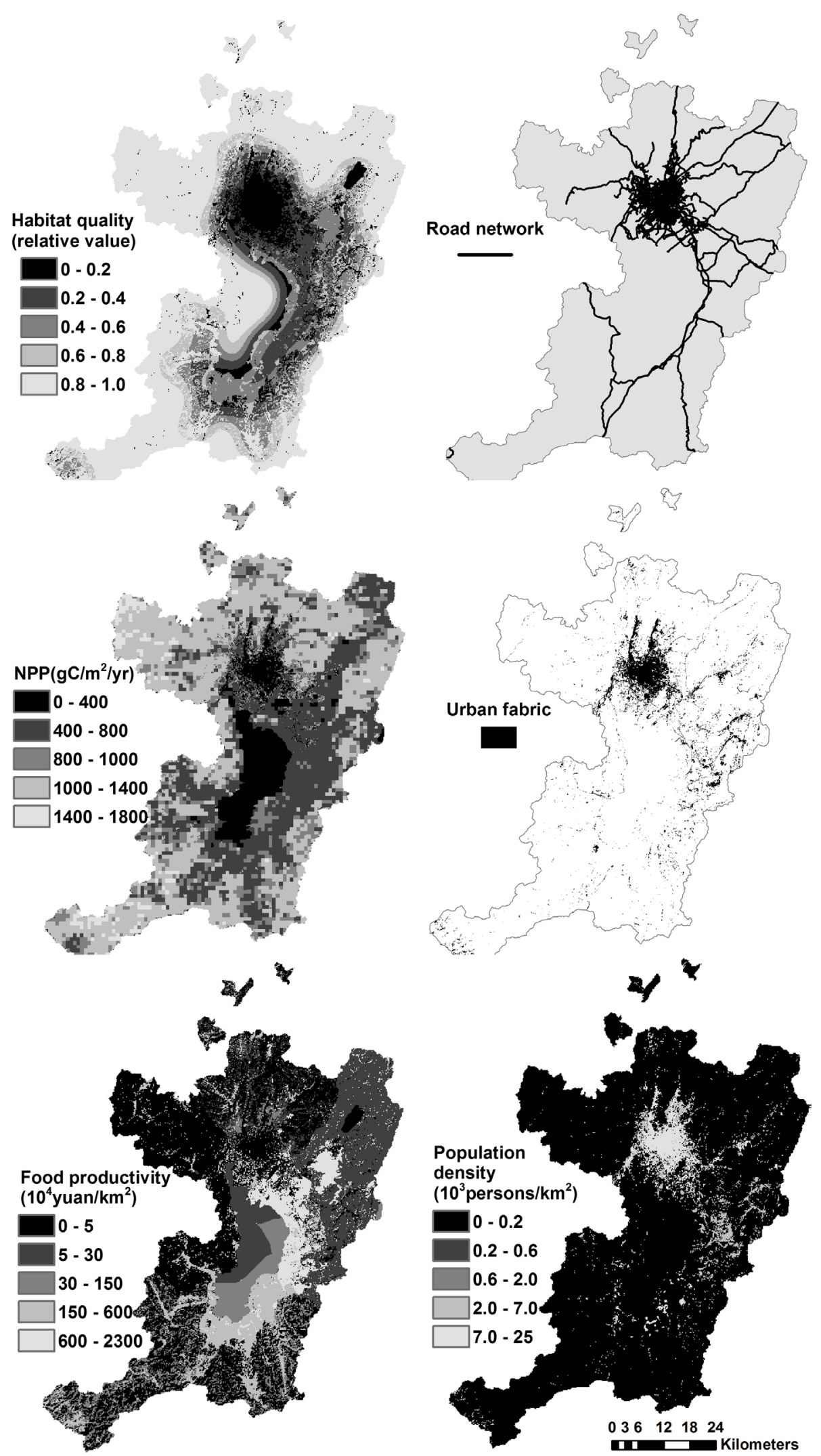

Figure 8: Spatial distributions of the three ecosystem services (left column) and the three socioeconomic items (right column) in the Kunming urban-rural area. NPP data are for 2006, road network relates to 2007 and the other four item are for 2010 

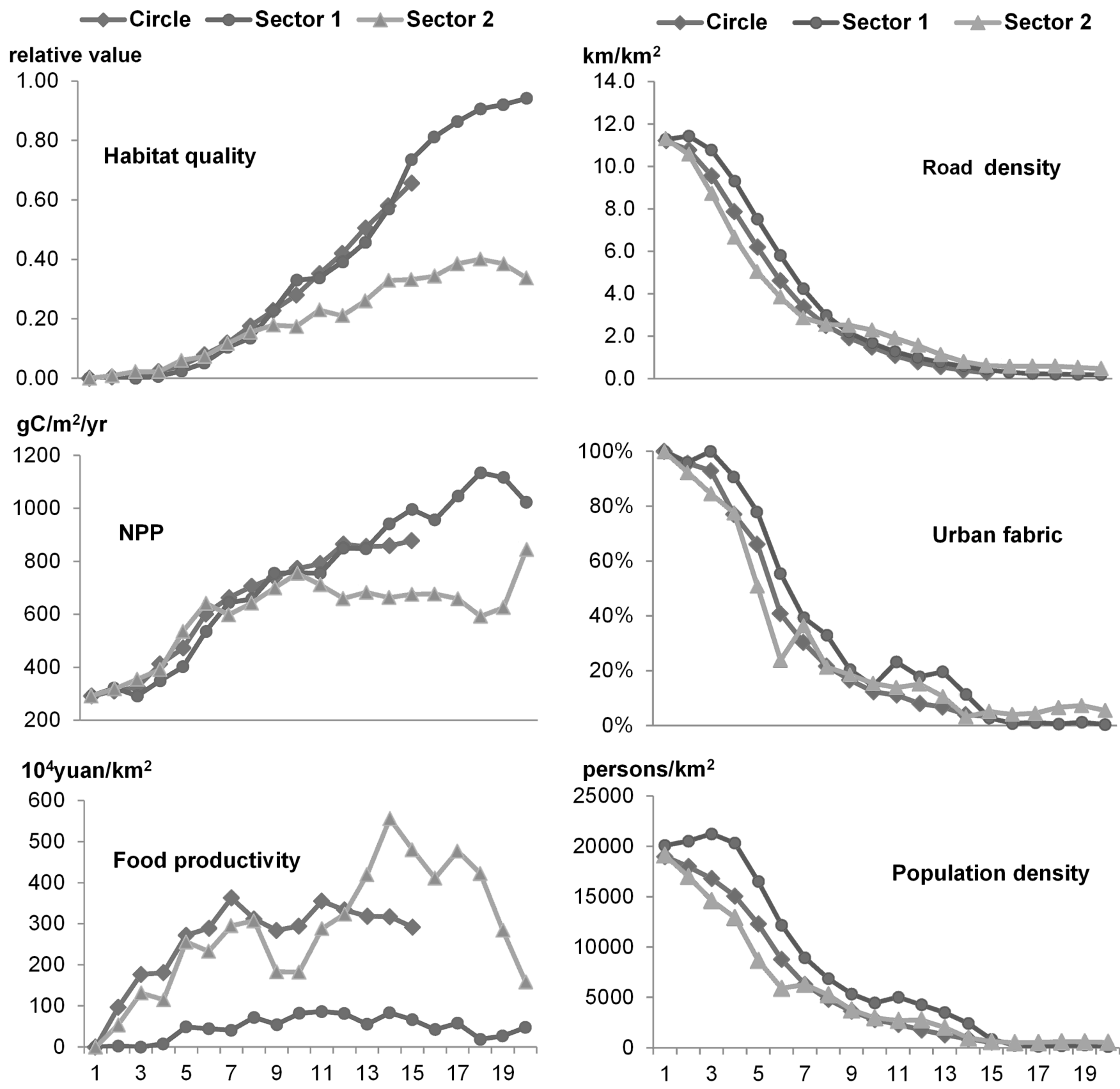

Figure 9: Gradients of the three ecosystem services (left column) and the three socioeconomic dimensions (right column) in the circle and sector areas of the Kunming urban-rural area. The X-axis is the distance in kilometers from the city center of Kunming. The $\mathrm{Y}$-axis is the average value of the indicators in the associated concentric ring or concentric sector ring of the circle or sectors

remained stable at a low level along the gradient. This characteristic was considerably different from food supply along the two sector gradients of Leipzig, which can be characterized by marked fluctuations.

With respect to the socioeconomic gradients, the two research areas provided significant consistencies with the three identical indicators. The urban rural gradients of road density and urban fabric of Kunming were apparently negative and considerably similar to those of Leipzig, respectively. These similarities occurred in all the three investigated areas. The most significant difference was that Kunming showed smoother trends of the indicator 
values than Leipzig. Population density also showed similarities between the two research areas by generally keeping dropping in the three analyzed gradient areas. The distinctions primarily existed in the first few concentric ring areas. In Leipzig, population density turned to drop quickly from the peak to zero from the third concentric ring in all the three gradient patterns. Contrarily, in the three analyzed areas of Kunming, population densities did not show apparent turning points and the declining velocities were lower than that of Leipzig.

\subsection{Linkages between ecosystem service and socio- economic gradients}

\section{Leipzig}

In Leipzig urban-rural area, some ecosystem service gradients showed similarities to that of socioeconomics; whereas, some others showed noticeable differences (Figure 6 and 7). The gradients of habitat quality, f-evapotranspiration, food supply and energy supply were significantly negatively correlated with the gradients of road density, urban fabric and population density in the circle and the two sector areas with $\mathrm{P}<0.01$ (Table 2). The sole exception was the weaker correlation between energy supply and road density in sector 1 , which was still significant at the 0.05 level. The gradient of above ground carbon storage was significantly positively correlated with the gradients of road density, urban fabric and population density in the circle and sector 1 areas. However, in sector 2, the linkages were much looser.

For the other three socioeconomic gradients, household size, housing area and unemployment rate, their correlations with the ecosystem service gradients were not as regular as road density, urban fabric or population density. For example, the correlations of household size with habitat quality, food supply and energy supply were not significant in sector 1. Furthermore, it was only negatively correlated with above ground carbon storage in the circle area. However, for its linkage with f-evapotranspiration, highly significant correlations were found in all the three areas. With regard to housing area and unemployment rate, their correlations with the five ecosystem services showed even more divergences. For instance, housing area was significantly negatively correlated with habitat quality solely in sector 1 and positively correlated with above ground carbon storage solely in the circle area. Whereas, its correlation with energy supply showed significance in all the three gradient areas. Regarding unemployment rate, positive significant correlations were solely found with habitat quality, f-evapotranspiration, food supply and energy supply in the circle area. In contrast, it had no significant correlations with the five ecosystem services in sector 1 . Even more unexpectedly, it was negatively correlated with food supply and energy supply in sector 2.

\section{Kunming}

Ecosystem service-socioeconomic linkages can also be identified along the urban-rural gradient of Kunming (Figure 9). The marked increases of habitat quality in the three analyzed areas were noticeably contrary to the declining trends of road density, urban fabric and population density in the three areas. The NPP gradient in the circle area also showed opposite trend to the gradients of these three socioeconomic dimensions in the circle areas. The correlations between ecosystem service and socioeconomic gradients of Kunming presented more consistency than that of Leipzig (Table 3). Habitat quality and NPP both showed strongly negative correlations with road density, urban fabric and population density at the 0.01 significance level in the circle and the two sector areas.

Unexpected finding refers to the linkages of food productivity gradients with those of road density, urban fabric and population density in sector 1 . Unlike the circle and sector 2 areas, where food productivity gradients were significantly negatively correlated with the three socioeconomic gradients, sector 1 did not exhibit close correlations between this service and the three socioeconomic dimensions. 
Table 2: Spearman correlations between the ecosystem service and socioeconomic gradients of the circle and sector areas in the Leipzig urban-rural area. The sample values are the mean values of the indicators in the associated rings with all sample sizes of 25 ( 25 concentric rings in the circle area and 25 concentric sector rings in both of the two

\begin{tabular}{|c|c|c|c|c|c|c|c|c|c|c|c|c|c|c|c|c|}
\hline \multirow[b]{3}{*}{$\begin{array}{l}\text { Road } \\
\text { density }\end{array}$} & & \multicolumn{3}{|c|}{ Habitat quality } & \multicolumn{3}{|c|}{$\begin{array}{l}\text { Above ground carbon } \\
\text { storage }\end{array}$} & \multicolumn{3}{|c|}{ f-evapotranspiration } & \multicolumn{3}{|c|}{ Food supply } & \multicolumn{3}{|c|}{ Energy supply } \\
\hline & & Circle & Sector 1 & Sector 2 & Circle & Sector 1 & Sector 2 & Circle & Sector 1 & Sector 2 & Circle & Sector 1 & Sector 2 & Circle & Sector 1 & Sector 2 \\
\hline & $\begin{array}{l}\text { Circle } \\
\text { Sector } 1 \\
\text { Sector } 2\end{array}$ & $-0.927^{* *}$ & $-0.769^{* *}$ & $-0.876^{* *}$ & $0.502^{*}$ & $0.425^{*}$ & -0.244 & $-0.928^{* *}$ & $-0.640^{* *}$ & $-0.849^{* *}$ & $-0.845^{* *}$ & $-0.744^{* *}$ & $-0.622^{* *}$ & $-0.726^{* *}$ & $-0.472^{*}$ & $-0.724^{* *}$ \\
\hline $\begin{array}{l}\text { Urban } \\
\text { fabric }\end{array}$ & $\begin{array}{l}\text { Circle } \\
\text { Sector } 1 \\
\text { Sector } 2\end{array}$ & $-0.879^{* *}$ & $-0.771^{* *}$ & $-0.940^{* *}$ & $0.675^{* *}$ & $0.454^{*}$ & -0.205 & $-0.901^{* *}$ & $-0.698^{* *}$ & $-0.800^{* *}$ & $-0.825^{* *}$ & $-0.651^{* *}$ & $-0.668^{* *}$ & $-0.797^{* *}$ & $-0.548^{* *}$ & $-0.735^{* *}$ \\
\hline $\begin{array}{l}\text { Population } \\
\text { density }\end{array}$ & $\begin{array}{l}\text { Circle } \\
\text { Sector } 1 \\
\text { Sector } 2\end{array}$ & $-0.860^{* *}$ & $-0.878^{* *}$ & $-0.937^{* *}$ & $0.513^{* *}$ & $0.649^{* *}$ & $-0.432^{*}$ & $-0.919^{* *}$ & $-0.566^{* *}$ & $-0.885^{* *}$ & $-0.897^{* *}$ & $-0.780^{* *}$ & $-0.547^{* *}$ & $-0.616^{* *}$ & $-0.631^{* *}$ & $-0.713^{* *}$ \\
\hline $\begin{array}{l}\text { Household } \\
\text { size }\end{array}$ & $\begin{array}{l}\text { Circle } \\
\text { Sector } 1 \\
\text { Sector } 2\end{array}$ & $0.791^{* *}$ & 0.225 & $0.567^{* *}$ & $-0.631^{* *}$ & -0.181 & 0.065 & $0.809^{* *}$ & $0.588^{* *}$ & $0.652^{* *}$ & $0.792^{* *}$ & 0.253 & $0.634^{* *}$ & $0.756^{* *}$ & 0.300 & $0.688^{* *}$ \\
\hline $\begin{array}{l}\text { Housing } \\
\text { area }\end{array}$ & $\begin{array}{l}\text { Circle } \\
\text { Sector } 1 \\
\text { Sector } 2\end{array}$ & -0.197 & $-0.563^{* *}$ & -0.259 & $0.574^{* *}$ & 0.232 & 0.282 & -0.242 & $-0.555^{* *}$ & $-0.477^{*}$ & -0.185 & $-0.426^{*}$ & $-0.655^{* *}$ & $-0.528^{* *}$ & $-0.421^{*}$ & $-0.516^{* *}$ \\
\hline $\begin{array}{l}\text { Unem- } \\
\text { ployment } \\
\text { rate }\end{array}$ & $\begin{array}{l}\text { Circle } \\
\text { Sector } 1 \\
\text { Sector } 2\end{array}$ & $0.903^{* *}$ & 0.246 & -0.152 & -0.351 & 0.041 & 0.325 & $0.800^{* *}$ & -0.327 & -0.320 & $0.777^{* *}$ & .000 & $-0.591^{* *}$ & $0.552^{* *}$ & -0.157 & $-0.453^{*}$ \\
\hline
\end{tabular}

Table 3: Spearman correlations between the ecosystem services and socioeconomic gradients of the circle and sector areas in Kunming urban-rural area. The sample values are the mean values of the indicators in the associated rings. The sample sizes are 15 for the circle area and 20 for the sectors (15 concentric rings in the circle area and 20 concentric sector rings in both of the two sectors). ${ }^{* *} \mathrm{P}<0.01, * \mathrm{P}<0.05$

\begin{tabular}{|c|c|c|c|c|c|c|c|c|c|c|}
\hline & & \multicolumn{3}{|c|}{ Habitat quality } & \multicolumn{3}{|l|}{ NPP } & \multicolumn{3}{|c|}{ Food productivity } \\
\hline & & Circle & Sector 1 & Sector 2 & Circle & Sector 1 & Sector 2 & Circle & Sector 1 & Sector 2 \\
\hline \multirow{3}{*}{$\begin{array}{l}\text { Road } \\
\text { density }\end{array}$} & Circle & $-1.000^{* *}$ & & & $-0.989 * *$ & & & $-0.736^{* *}$ & & \\
\hline & Sector 1 & & $-0.995^{* *}$ & & & $-0.977 * *$ & & & -0.375 & \\
\hline & Sector 2 & & & $-0.971 * *$ & & & $-0.629 * *$ & & & $-0.642^{* *}$ \\
\hline \multirow{3}{*}{$\begin{array}{l}\text { Urban } \\
\text { fabric }\end{array}$} & Circle & $-1.000^{* *}$ & & & $-0.989 * *$ & & & $-0.736^{* *}$ & & \\
\hline & Sector 1 & & $-0.976^{* *}$ & & & $-0.973^{* *}$ & & & -0.384 & \\
\hline & Sector 2 & & & $-0.928^{* *}$ & & & $-0.657^{* *}$ & & & $-0.789 * *$ \\
\hline \multirow{3}{*}{$\begin{array}{l}\text { Population } \\
\text { density }\end{array}$} & Circle & $-1.000 * *$ & & & $-0.989 * *$ & & & $-0.736^{* *}$ & & \\
\hline & Sector 1 & & $-0.982 * *$ & & & $-0.970 * *$ & & & -0.398 & \\
\hline & Sector 2 & & & $-0.972^{* *}$ & & & $-0.642^{* *}$ & & & $-0.687^{* *}$ \\
\hline
\end{tabular}




\section{Discussion}

\subsection{Relationships between ecosystem service and socioeconomic gradients}

\section{Leipzig}

As described in the results section, the gradients of habitat quality, f-evapotranspiration, food supply and energy supply had significantly negative correlations with the gradients of road density, urban fabric and population density in the circle and the two sector areas. Thesefindingsare logicalas the share of artificial surfaces in the total area generally kept declining and the vegetation cover proportion (mainly including forest, grassland and agricultural areas) appeared with an increasing trend along the gradient (Figure 3). In other words, it is the land cover variabilities in urban-rural areas that build the linkages between ecosystem services and socioeconomics. The close connections between ecosystem service supplies and land cover patterns in urban-rural areas have been evidenced by an extensive body of literature (Burkhard et al., 2012; Haase et al., 2012; Kroll et al., 2012; Larondelle and Haase, 2013). High habitat quality (or biodiversity) and evapotranspiration are usually due to intensive natural vegetation (Burkhard et al., 2009; Schwarz et al., 2011; Tallis et al., 2013). Food supply is undoubtedly attributed to agricultural land and energy, as estimated in this research, is mainly provided by peripheral areas of cities. Although not as much as ecosystem services, the spatial characteristics of socioeconomics have been investigated in the land cover context of urbanrural areas by some studies (Hope et al., 2003; Luck et al., 2009). With regard to the direct relationships between ecosystem services and socioeconomic elements, we found limited literature. Among these studies, one provided by Buyantuyev and $\mathrm{Wu}$ (2010) revealed the negative correlation between daytime surface temperature and median family income in the Phoenix metropolitan region. Another source from the same area additionally reported a positive relationship between mean temperature and population density (Jenerette et al., 2007). This finding can to some extent prove the correlation between f-evapotranspiration and population density in our research because evapotranspiration tends to go in an opposite direction of temperature in urban-rural gradients (Adler and Tanner, 2013).

Looking into the possible reasons for the irregular correlations of the gradients of household size, housing area and unemployment rate with the ecosystem service gradients, we assumed that the uneven spatial variations of household size, housing area and unemployment rate had done major contributions (see the irregular gradients of these three indicators in Figure 7). These irregular spatial dynamics should originate from more complex socioeconomic determinants of these three elements compared to road density, urban fabric and population density.

\section{Kunming}

As found in this research, habitat quality and NPP had significantly negative correlations with road density, urban fabric and population density in the circle and the two sector areas. These findings agree with the gradient characteristics of the five indicators. In other words, the three socioeconomic dimensions presented apparent decreasing trends and the two ecosystem services showed opposing trends along the gradient in all the three areas (Figure 9). The determinants of these phenomena should be the spatial dynamic characteristics of land covers as the values of all these five indicators are strongly associated with the land cover status (Burkhard et al., 2009; Hawbaker et al., 2005; Helmut Haberl, 2001; Kroll and Kabisch, 2012). For the spatial variations of land covers, the gradients showed noticeable declines of urban area shares and general increases of forest and grassland shares in all the three areas (Figure 4). The phenomenon that food productivity didn't show close correlations with the three socioeconomic dimensions in sector 1 can be easily explained by the ignorable proportion of cropland along the gradient of sector 1 (Figure 4, also see the land cover map in Figure 2).

\subsection{Comparisons between gradient patterns and case study areas}

As described in the results section, some ecosystem services showed similar spatial variations in the 
three gradient types (the circle and the two sectors areas) in the Leipzig and the Kunming urban-rural areas. Others, such as food supply, above ground carbon storage and energy supply of Leipzig and food productivity of Kunming presented different gradient patterns (Figure 6 and 9). These variation divergences are understandable when looking into the land cover characteristics of the different gradient patterns. For example, forest and semi-natural areas intensively emerged in the southeast of sector 2 area of Leipzig (Figure 1), causing the sharp increase and the two peaks of above ground carbon storage after the 15th concentric sector ring (Figure 6). The differences of the gradient patterns of ecosystem services in different areas imply that although the concentric ring gradient pattern can comprehensively capture the spatial variation information along the urbanrural gradient, it can be unsuitable in some cases. For instance, it is problematic when the land cover structure does not exhibit the same pattern in all directions from the city center as shown by the two study areas in this research. In the regions with unique land cover patterns (e.g., sector 1 and 2 of Leipzig and sector 2 of Kunming in this study), refined gradient patterns that can more accurately capture the details of the whole research area will be more preferable. These gradient patterns include the concentric sector ring gradient proposed in this study and the transect gradient used in some other research (Banzhaf et al., 2009; Hahs and McDonnell, 2006; Luck and $\mathrm{Wu}, 2002$ ). Having said this, as the concentric sector ring and the transect gradients rely on directions, they can solely treat the chosen directions and lose the information of the regions in other directions. Considering the advantages and disadvantages of different gradient patterns, a combination of them can be a promising solution to both comprehensively and detailedly investigate ecosystem service gradients.

Compared to ecosystem services, the investigated socioeconomic dimensions presented much more consistency between the three gradient areas of both Leipzig and Kunming. The major disagreements referred to household size, housing area and unemployment rate of Leipzig (Figure 7). As discussed earlier, these three aspects are affected by more complex socioeconomic reasons compared to road density, urban fabric and population density, which are primarily based on urbanization levels (Hahs and McDonnell, 2006). Accordingly, we assume that the concentric ring gradient is appropriate to reveal the spatial dynamics of road density, urban fabric and population density in urban-rural gradients. Whereas, gradient patterns that can capture details (e.g., concentric sector ring and transect) are additionally required to treat more complex socioeconomic dimensions, such as household size, housing area and unemployment rate.

Comparing different study areas, we found limited ecosystem services presenting similar gradient patterns in urban-rural area. Different regions tend to exhibit divergent spatial variation characters of ecosystem services from the city center to outskirts. For example, with respect to f-evapotranspiration and above ground carbon storage, our findings in Leipzig are inconsistent with those from Larondelle and Haase (2013) in several other European cities. Their results also showed divergent ecosystem service gradient patterns in urban-rural areas of different regions. According, we can induce that although ecosystem service gradients in certain patterns can be found in urban-rural areas, typical gradient patterns suiting different regions are scarcely exiting. In other words, the gradient patterns of ecosystem services found in our study cannot be generalized to other cities. The possible reason, as we mentioned before, are the distinct land cover structures and distributions of different urban-rural regions.

With respect to socioeconomic dimensions, identical urban-rural gradients have been found between the two study areas in our study. Additionally, similar gradient patterns are identified in other studies. For example, Leipzig and Kunming have identical urban fabric gradients patterns (Figure 7 and 9), which are similar to the ones of Manchester, Berlin, Hamburg as well as Munich delineated by Kroll and Müller (2011) and Kroll and Kabisch (2012). With regard to population density, consistency of urban-rural gradient patterns exit between Leipzig (this study) and Berlin, Hamburg and Munich (Kroll and Müller, 2011) and between Kunming (this study) and Warsaw (Kroll and Müller, 2011). Regarding the three more intricate socioeconomic dimensions, household size, housing area and unemployment rate, urban-rural 
gradient patterns primarily present disagreements between different regions (e.g., household size between Leipzig in this study and Hamburg and Munich in the research of Kroll and Kabisch (2012) and housing area between Leipzig and Manchester and Hamburg presented by Kroll and Müller (2011)). To sum up, we can tentatively assume the existence of typical gradient patterns of some socioeconomic dimensions (e.g., urban fabric discussed above) in different urban-rural areas.

\subsection{Uncertainty analysis}

An ecosystem service assessment is always accompanied by uncertainties originating from the complexity of the ecological system, respondents' preferences and technical problems (Hou et al., 2013; Elmqvist et al., 2010; Scolozzi et al., 2011). In this research, the creation of gradients relied on averaging the values of heterogeneous ecosystem services and socioeconomic dimensions in each ring area, leading to uncertainties with the produced gradient. These uncertainties may cause bias in assessment ( $\mathrm{Li}$ and $\mathrm{Wu}, 2006$ ), such as unreliable characterization of gradients and doubtable revelations of relationships between ecosystem services and socioeconomics. Therefore, it is imperative to obtain the information of uncertainties with the results. Considering the large number of ecosystem services and socioeconomic dimensions investigated in this study, we solely chose four of them as examples to quantify the uncertainties of gradients in the three gradient areas (the circle and the two sectors). The analyzed indicators are above ground carbon storage and housing area of Leipzig and habitat quality and population density of Kunming. Referring to the mainstreaming methods showing uncertainties with value averaging in ecosystem service studies (Larondelle and Haase, 2013; Yanai et al., 2010; Zhu and Carreiro, 2004), we used standard deviation (SD) to show the value ranges of the four indicators in each ring of the circle area and the two sectors. Accordingly, uncertainty gradients of the four examined indicators were created (Figure 10).

In general, the established uncertainty gradients did not exhibit typical patterns. The magnitudes and changes of uncertainties were not depended on the magnitudes of the mean values or the distance from the city center. Taking the above ground carbon storage of Leipzig as an example, in sector 1 , the greatest uncertainty (greatest SD value) appeared at the 12th ring, where the mean value was not the highest among all the rings (Figure 10, b). In sector 2 , the uncertainties remained at low levels before the 15th ring and soared between the distance of $15 \mathrm{~km}$ and $24 \mathrm{~km}$ from the city center (Figure 10, c). Looking into the map of ecosystem services spatial distribution and the land cover map (Figure 1 and $5)$, we can attribute the considerable uncertainties in these rings to the divergences of the above carbon storage values and the heterogeneous land covers in these areas. For the other three indicators, it is also convenient to observe the uncertainty gradient patterns, compare the uncertainty magnitudes between different rings and find out the areas with most or least uncertainties. After testing this uncertainty gradient method, we assume that this method is appropriate to quantitatively capture the uncertainties in exploring ecosystem services and socioeconomic gradients in urban-rural areas.

\section{Conclusions}

In this article we draw on the urban-rural gradient principle to offer a methodology to investigate the linkages between ecosystem services and socioeconomics in urban-rural areas. Interesting findings were derived by performing empirical studies with the developed methods in two case urban-rural areas respectively in Germany and China. With these results, we can now answer the three research questions asked at the beginning of this article as follows:

1) The investigated ecosystem services and socioeconomic dimensions of the two study areas presented regularities of spatial patterns in urbanrural gradients in different degrees. Some of them showed either generally increasing or decreasing trends along urban-rural gradients, others exhibited considerable fluctuations. 


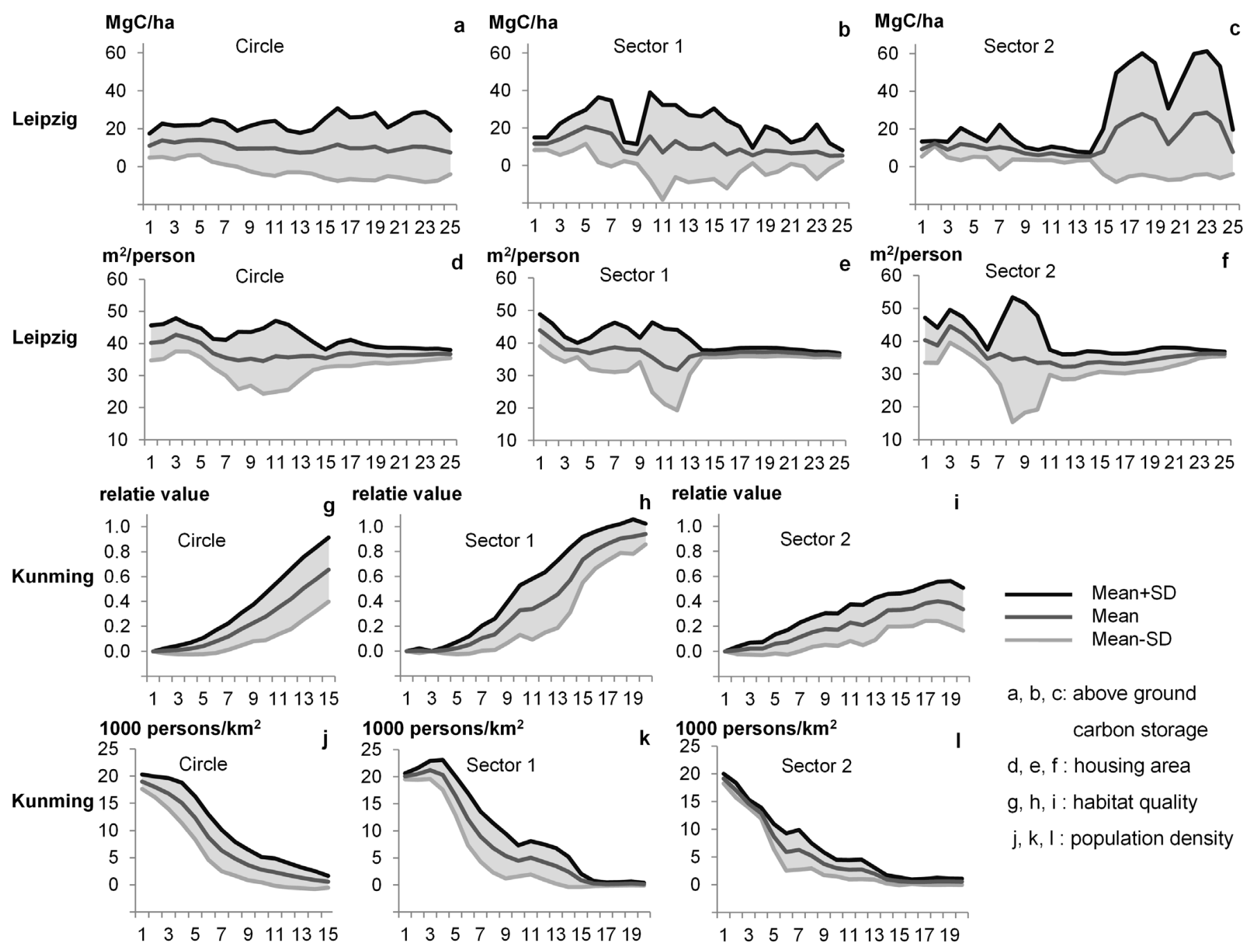

Figure 10: Quantified uncertainties of ecosystem services and socioeconomic gradient calculations for the Leipzig and Kunming urban-rural areas. The $\mathrm{X}$-axis is the distance in kilometers from the city center. Above ground carbon storage and housing area were investigated for Leipzig. Habitat quality and population density were analyzed for Kunming. Uncertainties were quantified by the ranges between the values of mean plus standard deviation (SD), mean values and the values of mean minus SD

2) Ecosystem service gradient characters of the circle and the two sector gradient areas presented more divergences than that of socioeconomic gradients in both the two study areas. The concentric ring gradient pattern can more comprehensively capture the overall spatial dynamics of ecosystem services and socioeconomics along the gradients. In contrary, the concentric sector ring gradient pattern can better reveal the details of especially concerned areas in specific directions from the city center. For the two study areas, urban-rural gradients of identical ecosystem services did not necessarily present consistent patterns and gradients of the same socioeconomic dimensions showed similar patterns.
3) Strong linkages between some ecosystem service and socioeconomic gradients were observed and statistically proven in both the two study areas. The socioeconomic dimensions more based on land covers had stronger correlations with ecosystem services. Moreover, the correlations of a certain pair of ecosystem service and socioeconomic gradients could be inconsistent in different gradient areas of either study area.

In addition, the results of our study suggest another two important messages. By integrating our findings and the published work, we further proved that a typical model of ecosystem services gradient does not exist for different cities. The other message 
tells the necessity to be aware of uncertainties and effectively incorporate uncertainty analysis into the investigations of ecosystem service and socioeconomic gradients.

Novel innovations in the field of ecosystem services are emerging regularly. In this exiting time we call for future research to determine whether our arguments for the interrelationships between ecosystem services and socioeconomics in urban-rural areas are supported by more empirical evidence. We hope this paper will help draw more research interests to elevate our understanding of human-environmental interactions in urban-rural systems.

\section{Acknowledgements}

$T$ his work was financially supported by the EU Integrated Project PLUREL (contract No. 036921) and the project "Regulation of Integrative Land Use in Urban-Rural Areas with Ecological Principles in Lake Catchments of the Yungui Plateau" funded by the Department of Land and Resources of Yunnan Province, China. We are grateful for the time and efforts from the anonymous reviewers on improving this paper.

\section{References}

Adler, F.R. \& C.J. Tanner 2013. Urban Ecosystems: Ecological Principles for the Built Environment. Cambridge University Press, Cambridge.

Alcamo, J.; van Vuuren, D. \& W. Cramer 2005. Changes in ecosystem services and their drivers across the scenarios. In: MA (eds.): Ecosystems and Human Well Being: Scenarios. Island Press; Washington, DC.

Banzhaf, E.; Grescho, V. \& A. Kindler 2009. Monitoring urban to peri-urban development with integrated remote sensing and GIS information: a Leipzig, Germany case study. International Journal of Remote Sensing 30, 1675-1696.
Bastian, O. 2013. The role of biodiversity in supporting ecosystem services in Natura 2000 sites. Ecological Indicators 24, 12-22.

Berry, B. \& A. Okulicz-Kozaryn 2011. An urban-rural happiness gradient. Urban Geography 32, 871883.

Burkhard, B.; Kandziora, M.; Hou, Y. \& F. Müller 2014. Ecosystem service potentials, flows and demands - Concepts for spatial localisation, indication and quantification. Landscape Online 34, 1-32.

Burkhard, B.; Kroll, F. \& F. Müller 2009. Landscapes' capacities to provide ecosystem services - A concept for land-cover based assessments. Landscape Online 15, 1-22.

Burkhard, B.; Kroll, F.; Nedkov, S. \& F. Müller 2012. Mapping ecosystem service supply, demand and budgets. Ecological Indicators 21, 17-29.

Buyantuyev, A. \& J. Wu 2010. Urban heat islands and landscape heterogeneity: linking spatiotemporal variations in surface temperatures to land-cover and socioeconomic patterns. Landscape Ecology 25, 17-33.

Chinnaiah, B. \& V. Madhu 2010. Primary productivity of Darmasagar lake in Adilabad, Andhra Pradesh, India. International Journal of Pharmacy \& Life Sciences 1, 437-439.

Costanza, R.; D'Arge, R.; de Groot, R.; Farber, S.; Grasso, M.; Hannon, B.; Limburg, K.; Naeem, S.; O'Neill, R.V.; Paruelo, J.; Raskin, R.G.; Sutton, P. \& M. van den Belt 1997. The value of the world's ecosystem services and natural capital. Nature 387, 253-260.

Couch, C. \& J. Karecha 2006. Controlling urban sprawl: Some experiences from Liverpool. Cities 23, 353-363.

de Groot, R.S.; Alkemade, R.; Braat, L.; Hein, L. \& L. Willemen 2010. Challenges in integrating the 
concept of ecosystem services and values in landscape planning, management and decision making. Ecological Complexity 7, 260-272.

Dow, K. 2000. Social dimensions of gradients in urban ecosystems. Urban Ecosystems 4, 255-275.

Duraiappah, A.K. 2011. Ecosystem services and human well-being: Do global findings make any sense? Bioscience 61, 7-8.

Elmqvist, T.; Maltby, E.; Barker, T.; Mortimer, M. \& C. Perrings 2010. Biodiversity, ecosystems and ecosystem services. In: P. Kumar (ed.): The Economics of Ecosystems and Biodiversity: Ecologic and Economic Foundations. Earthcan; London \& Washington, DC, pp. 41-111.

Fachagentur für Nach wachsende Rohstoffe e.V. 2014. http://www.fnr.de/ (Date: 22.1.2015).

Federal Agency for Cartography and Geodesy $2014 . \quad$ http://www.bkg.bund.de/DE/Home/ homepage_node.html_nnn=true_ (Date: 22.1.2015).

Geospatial Information and Surveying, Saxony 2014. http://www.landesvermessung.sachsen.de/ (Date: 22.1.2015).

German Federal Environmental Agency 2014. German Aerospace Center 2010. CORINE Land Cover 2006. http://www.corine.dfd.dlr.de/intro_ de.html (Date: 22.1.2015).

Gibbs H.K 2006. Olson's major world ecosystem complexes ranked by carbon in live vegetation: An updated database using the GLC2000 land cover product. http://cdiac.ornl.gov/epubs/ndp/ ndp017/ndp017b.html (Date: 22.1.2015).

Haase, D.; Schwarz, N.; Strohbach, M.; Kroll, F. \& R. Seppelt 2012. Synergies, Trade-offs, and losses of ecosystem services in urban regions: An integrated multiscale framework applied to the Leipzig-Halle region, Germany. Ecology and Society 17, 22.
Haberl, H.; Erb, K. \& F. Krausmann 2001. Changes in ecosystem processes induced by land use: Human appropriation of aboveground NPP and its influence on standing crop in Austria. Global Biogeochemical Cycles 15, 929-942.

Hahs, A.K. \& M.J. McDonnell 2006. Selecting independent measures to quantify Melbourne's urban-rural gradient. Landscape and Urban Planning 78, 435-448.

Haines-Young, R. \& M. Potschin 2010. The links between biodiversity, ecosystem services and human well-being. In: D. Raffaelli \& C. Frid (eds.): Ecosystem Ecology: A New Synthesis. BES Ecological Reviews Series. CUP; Cambridge, pp. 110-139.

Hawbaker, T.J.; Radeloff, V.C.; Hammer, R.B. \& M.K. Clayton 2005. Road density and landscape pattern in relation to housing density, and ownership, land cover, and soils. Landscape Ecology 20, 609625.

Hope, D.; Gries, C.; Zhu, W.X.; Fagan, W.F.; Redman, C.L.; Grimm, N.B.; Nelson, A.L.; Martin, C. \& A. Kinzig 2003. Socioeconomics drive urban plant diversity. Proceedings of the National Academy of Sciences of the United States of America 100, 8788-8792.

Hou, Y.; Burkhard, B. \& F. Müller 2013. Uncertainties in landscape analysis and ecosystem service assessment. Journal of Environmental Management 127, Supplement, S117-S131.

Hou, Y.; Zhou, S.; Burkhard, B. \& F. Müller 2014. Socioeconomic influences on biodiversity, ecosystem services and human well-being: A quantitative application of the DPSIR model in Jiangsu, China. Science of the Total Environment 490, 1012-1028.

Ingraham, M.W. \& S.G. Foster 2008. The value of ecosystem services provided by the U.S. National Wildlife Refuge System in the contiguous U.S. Ecological Economics 67, 608-618. 
Institute for Energy and Environment 2007. Schlüsseldaten Klimagasemissionen. http:// www.ufop.de/files/6813/3918/4231/Bericht_ Klimagas.pdf (Date: 22.1.2015).

Jansson, A. \& S. Polasky 2010. Quantifying biodiversity for building resilience for food security in urban landscapes: Getting down to business. Ecology and Society 15.

Jenerette, G.D.; Harlan, S.L.; Brazel, A.; Jones, N.; Larsen, L. \& W.L. Stefanov 2007. Regional relationships between surface temperature, vegetation, and human settlement in a rapidly urbanizing ecosystem. Landscape Ecology 22, 353-365.

Kandziora, M.; Burkhard, B. \& F. Müller 2013. Interactions of ecosystem properties, ecosystem integrity and ecosystem service indicators-A theoretical matrix exercise. Ecological Indicators 28, 54-78.

Kroll, F. \& N. Kabisch 2012. The relation of diverging urban growth processes and demographic change along an urban-rural gradient. Population Space and Place 18, 260-276.

Kroll, F. \& F. Müller 2011. Can the principle of self-organized gradients be applied for human systems. International Journal of Design \& Nature and Ecodynamics 6, 90-108.

Kroll, F.; Müller, F.; Haase, D. \& N. Fohrer 2012. Ruralurban gradient analysis of ecosystem services supply and demand dynamics. Land Use Policy 29, 521-535.

KTBL 2005. Faustzahlen für die Landwirtschaft. KTBL-Schriftenvertrieb im Landwirtschaftsverlag, Münster-Hiltrup.

Larondelle, N. \& D. Haase 2013. Urban ecosystem services assessment along a rural-urban gradient: A cross-analysis of European cities. Ecological Indicators 29, 179-190.
Lautenbach, S.; Kugel, C.; Lausch, A. \& R. Seppelt 2011. Analysis of historic changes in regional ecosystem service provisioning using land use data. Ecological Indicators 11, 676-687.

Leipzig Amt für Statistik und Wahlen 2009. Statistisches Jahrbuch. Stadt Leipzig, Amt für Statistik und Wahlen (in German).

Li, H. \& J. Wu 2006. Uncertainty analysis in ecological studies: An overview. In: J. Wu; K.B. Jones; H. Li \& O.L. Loucks (eds.): Scaling and Uncertainty Analysis in Ecology. Springer; Netherlands, pp. 45.

Lin, W.; Wang, C.; Zhao, M.; Huang, J.; Shi, R.; Liu, Y. \& J. Gao 2008. Estimation urban forests NPP based on forest inventory data and remote sensing. Ecology and Environment 17, 766-770 (in Chinese).

Luck, G.W.; Smallbone, L.T. \& R. O’Brien 2009. Socio-economics and vegetation change in urban ecosystems: patterns in space and time. Ecosystems 12, 604-620.

Luck, M. \& J. Wu 2002. A gradient analysis of urban landscape pattern: a case study from the Phoenix metropolitan region, Arizona, USA. Landscape Ecology 17, 327-339.

MA 2005. Ecosystems and Human Well-beingSynthesis. Island Press, Washington DC.

McDonnell, M.J. \& A.K. Hahs 2008. The use of gradient analysis studies in advancing our understanding of the ecology of urbanizing landscapes: current status and future directions. Landscape Ecology 23, 1143-1155.

McDonnell, M.J. \& S.T.A. Pickett 1990. Ecosystem structure and function along urban-rural gradients: An unexploited opportunity for ecology. Ecology 71, 1232-1237. 
McDonnell, M.J.; Pickett, S.T.A.; Groffman, P.; Bohlen, P.; Pouyat, R.; Zipperer, W.; Parmelee, R.; Carreiro, M. \& K. Medley 1997. Ecosystem processes along an urban-to-rural gradient. Urban Ecosystems 1, 21-36.

Melillo, J.M.; McGuire, A.D.; Kicklighter, D.W.; Moore, B.; Vorosmarty, C.J. \& A.L. Schloss 1993. Global climate change and terrestrial net primary production. Nature 363, 234-240.

Ministry of Agriculture and Environment SaxonyAnhalt 2007. Biomassepotenzialstudie 2007 für das Land Sachsen-Anhalt, Magdeburg.

Müller, F. \& B. Burkhard 2012. The indicator side of ecosystem services. Ecosystem Services 1, 26-30.

National Bureau of Statistics of China 2011. China City Statistical Year Book 2011. China Statistic Press, Beijing (in Chinese).

Nelson et al. 2005. Drivers of change in ecosystem condition and services. In: MA (eds.): Ecosystems and Human Well Being: Scenarios. Island Press; Washington, DC, pp. 173-222.

Nuissl, H. \& D. Rink 2005. The 'production' of urban sprawl in eastern Germany as a phenomenon of post-socialist transformation. Cities 22, 123-134.

Numerical Terradynamic Simulation Group 2013. MODIS GPP/NPP Project (MOD17). http://www. ntsg.umt.edu/project/mod17 (Date: 22.1.2015).

Piorr, A.; Ravetz, J. \& Tosics, I. (eds.) 2011. Periurbanisation in Europe: Towards a European Policy to Sustain Urban-Rural Futures, University of Copenhagen/Academic Books Life Sciences. p144.

Pouyat, R.V. \& M.J. McDonnel 1991. Heavy-metal accumulations in forest soils along an urban-rural gradient in southeastern new-york, UAS. Water Air and Soil Pollution 57-8, 797-807.
Radford, K.G. \& P. James 2013. Changes in the value of ecosystem services along a rural-urban gradient: A case study of Greater Manchester, UK. Landscape and Urban Planning 109, 117-127.

Raudsepp-Hearne, C.; Peterson, G.D.; Tengo, M.; Bennett, E.M.; Holland, T.; Benessaiah, K.; MacDonald, G.K. \& L. Pfeifer 2010. Untangling the environmentalist's paradox: Why is human wellbeing increasing as ecosystem services degrade? Bioscience 60, 576-589.

Saxon Office of Statistics 2010. Population Statistics, territorial status. www.statistik.sachsen.de (Date: 22.1.2015).

Saxon State Ministry of the Environment and Agriculture 2007. Energie für die Zukunft, Sachsens Potenzial an nachwachsenden Rohstoffen/ Biomasse, Dresden.

Saxon Upper Mining Authority 2007. Jahresbericht 2007, Freiberg.

Schwarz, N.; Bauer, A. \& D. Haase 2011. Assessing climate impacts of planning policies-An estimation for the urban region of Leipzig (Germany). Environmental Impact Assessment Review 31, 97-111.

Scolozzi, R.; Morrib, E. \& R. Santolinib 2011. Delphibased change assessment in ecosystem service values to support strategic spatial planning in talian landscapes. Ecological Indicators 21, 134144.

Statistics Bureau of Kunming 2011. Kunming Statistical Year Book 2011. China Statistics Press, Beijing (in Chinese).

Strohbach, M.W. \& D. Haase 2012. Above-ground carbon storage by urban trees in Leipzig, Germany: Analysis of patterns in a European city. Landscape and Urban Planning 104, 95-104. 
Sun, L.; Chen, D.; Wang, Q.; Gao, Y. \& D. Jin 2011. Spatio-temporal distribution of chlorophyll a concentration and primary productivity between winter in 2009 and spring in 2010 of Lake Dianchi. Journal of Shanghai Normal University (Natural Sciences) 40, 191-196 (in Chinese).

Tallis, H.T.; Ricketts, T.; Guerry, A.D.; Wood, S.A.; Sharp, R.; Nelson, E.; Ennaanay, D.; Wolny, S.; Olwero, N.; Vigerstol, K.; Pennington, D.; Mendoza, G.; Aukema, J.; Foster, J.; Forrest, J.; Cameron, D.; Arkema, K.; Lonsdorf, E.; Kennedy, C.; Verutes, G.; Kim, C.K.; Guannel, G.; Papenfus, M.; Toft, J.; Marsik, M.; Bernhardt, J.; Griffin, R.; Glowinski, K.; Chaumont, N.; Perelman, A. \& M. Lacayo 2013. InVEST 2.5.5 User's Guide. The Natural Capital Project, Stanford.

TEEB 2010. The Economics of Ecosystems and Biodiversity: Ecological and Economic Foundations. Earthscan, London and Washington.

Yanai, R.D.; Battles, J.J.; Richardson, A.D.; Blodgett, C.A.; Wood, D.M. \& E.B. Rastetter 2010. Estimating uncertainty in ecosystem budget calculations. Ecosystems 13, 239-248.

Zhao, M. \& G. Zhou 2005. Estimation of biomass and net primary productivity of major planted forests in China based on forest inventory data. Forest Ecology and Management 207, 295-313.

Zhou, X. \& Y. Wang 2011. Spatial-temporal dynamics of urban green space in response to rapid urbanization and greening policies. Landscape and Urban Planning 100, 268-277.

Zhu, W. \& M.A. Carreiro 2004. Temporal and spatial variations in nitrogen transformations in deciduous forest ecosystems along an urban - rural gradient. Soil Biology \& Biochemistry 36, 267-278. 


\section{Appendix}

Table 4: Date uses, time, scales and sources for the study of Leipzig urban-rural area

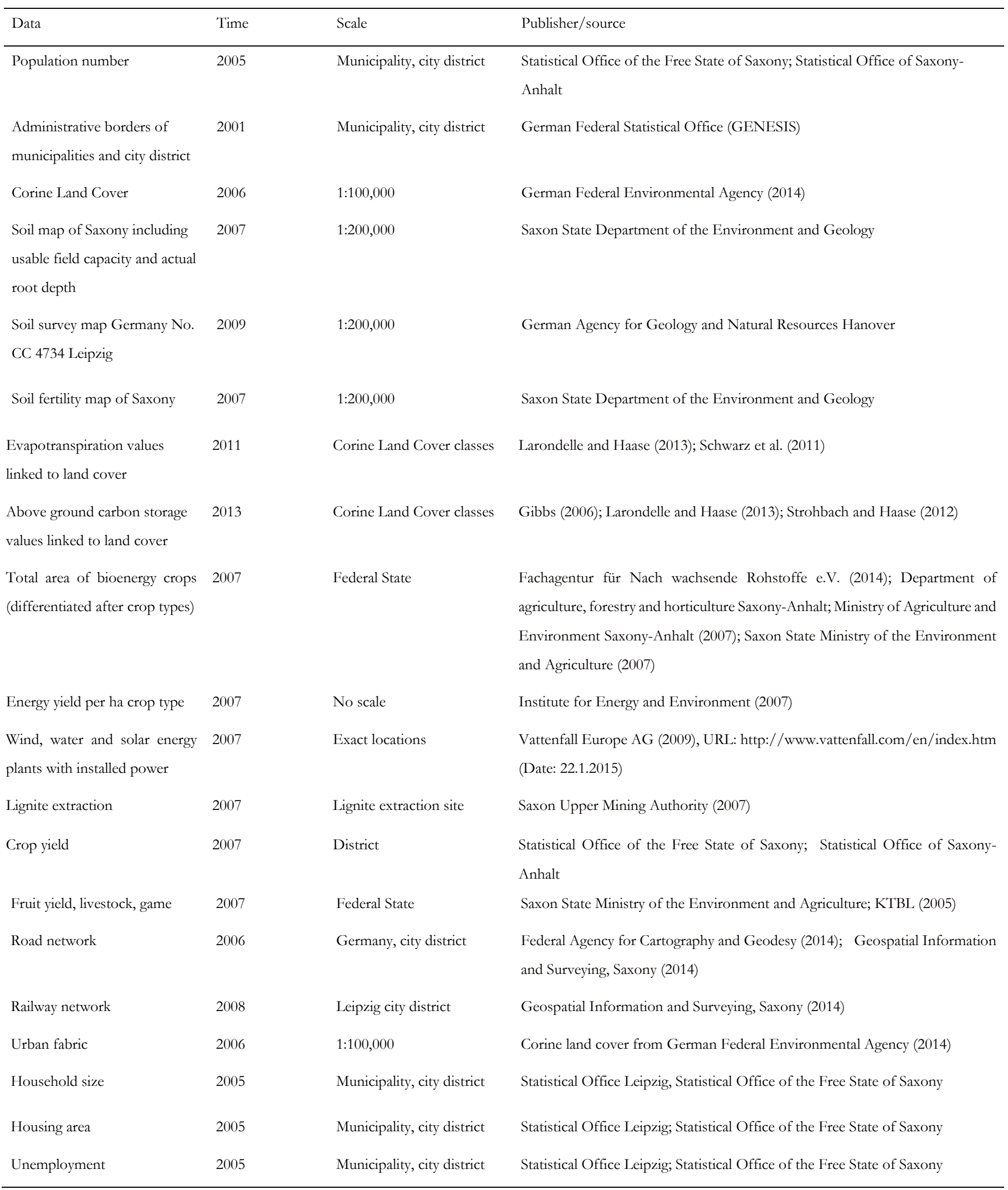


Table 5: Date uses, time, scales and sources for the study of Kunming urban-rural area

\begin{tabular}{|c|c|c|c|}
\hline Data & Time & Scale & Publisher/source \\
\hline $\begin{array}{l}\text { Administrative borders of } \\
\text { districts and counties }\end{array}$ & 2000 & 1:4,000,000, China & $\begin{array}{l}\text { Data Sharing Infrastructure of Earth System Science, } \\
\text { http://www.geodata.cn/Portal/?isCookieChecked=true } \\
\text { (Date: } 22.1 .2015)\end{array}$ \\
\hline Land cover map & 2010 & $\begin{array}{l}\text { 1:100,000, Kunming prefecture- } \\
\text { level city }\end{array}$ & $\begin{array}{l}\text { Produced by the interpretation of } 30 \text {-meter Landsat } \\
\text { thematic mapper (TM) data in combination of a } \\
1: 100,000 \text { topographic map of the research area }\end{array}$ \\
\hline $\begin{array}{l}\text { Net primary production } \\
\text { raster map for vegetation } \\
\text { covers }\end{array}$ & 2006 & $1 \mathrm{~km} \times 1 \mathrm{~km}$, global & Numerical Terradynamic Simulation Group (2013) \\
\hline $\begin{array}{l}\text { Net primary production of } \\
\text { urban area }\end{array}$ & 2006 & Shanghai city district & Lin et al. (2008) \\
\hline $\begin{array}{l}\text { Net primary production of } \\
\text { the Dianchi Lake }\end{array}$ & $\begin{array}{l}2009- \\
2010\end{array}$ & the Dianchi Lake & Sun et al. (2011); Chinnaiah and Madhu (2010) \\
\hline $\begin{array}{l}\text { Farming, animal husbandry } \\
\text { and fishery yields }\end{array}$ & 2010 & $\begin{array}{l}\text { Districts and counties, } \\
\text { Kunming }\end{array}$ & $\begin{array}{l}\text { Kunming Statistical Yearbook 2011, Statistics Bureau of } \\
\text { Kunming }\end{array}$ \\
\hline Road network & 2007 & China & $\begin{array}{l}\text { National Administration of Surveying, Mapping and } \\
\text { Geoinformation of China }\end{array}$ \\
\hline Urban fabric & 2010 & $\begin{array}{l}\text { 1:100,000, Kunming prefecture- } \\
\text { level city }\end{array}$ & Kunming Land and Resource Bureau \\
\hline Population density & 2010 & $\begin{array}{l}\text { Districts and counties, } \\
\text { Kunming }\end{array}$ & $\begin{array}{l}\text { Kunming Statistical Yearbook 2011, Statistics Bureau of } \\
\text { Kunming }\end{array}$ \\
\hline
\end{tabular}

